\title{
MODELLING AND EARTHQUAKE RESPONSE OF GISBORNE POST OFFICE SITE, NEW ZEALAND
}

\author{
J.X. Zhao ${ }^{1,2}$, P.N. Davenport ${ }^{1,2}$ and G.H. McVerry ${ }^{1,3}$
}

\begin{abstract}
SUMMARY
A non-linear soil model was established for estimating the earthquake response of the Gisborne Post Office site based on the results of geotechnical site investigation and laboratory testing on soil samples. The site was found to be very soft and susceptible to seismic amplification. The non-linear model was able to portray the response spectra of recorded motions reasonably well using modified records from a rock site with a thin layer of stiff soil. Sensitivity analysis showed that the ground surface spectra were not very sensitive to variation of the soil parameters over a plausible range. A suite of rock site records obtained from moderate and large magnitude earthquakes was used as the excitation for the non-linear model and the spectral ratios were expressed as functions of the spectral values of the bedrock excitation at the same period. The scatter of the spectral ratios was reasonably small and the cause of the scatter was found to be the different frequency content of bedrock excitations. For a very large bedrock motion, soil non-linearity caused deamplification with respect to the rock site spectra for periods up to the elastic period of the fundamental mode of the site, while spectral ratios changed little with the spectral values of bedrock excitations for periods much longer than the site period, indicating that soil non-linearity has little effect at long periods. These ratios were used to calculate a site-specific smoothed spectrum based on a probabilistic rock site spectrum for a given probability of exceedance. The smoothed spectrum is suitable for engineering design applications. Finally, a comparison was made of the results from an equivalent linear method employed in the SHAKE program and the non-linear analysis. For this very soft soil site, the difference in response spectra at short and intermediate periods by the two methods was found to be significant for moderate and large bedrock shaking.
\end{abstract}

\section{INTRODUCTION}

Ground response in earthquakes is often amplified by soft soil layers [1] and the amplification can cause significant structural damage as in the cases of Mexico City [2] and the Marina District, San Francisco [3]. In New Zealand, there are many soft soil sites susceptible to ground motion amplification. In the last few years, there has been on-going effort by the Institute of Geological and Nuclear Sciences in collecting strong-motion records from soil sites $[4,5]$, measuring soil material properties $[6,7]$ at sites of the New Zealand strong motion accelerograph network, and modelling of site responses.

To compute the non-linear response and amplification of a soil site for a given bedrock excitation, there are essentially two methods, i.e., elastic or non-linear analyses, that are often used. In the elastic approach, very complicated two- and threedimensional models can be used. In a non-linear soil site analysis, because of the large computational effort in dealing with soil non-linearity, one-dimensional modelling is often used for engineering practice and occasionally two-dimensional modelling [8]. The best direct comparison of 1-, 2- and 3dimensional modelling is possibly the statistical analysis of the

\footnotetext{
${ }^{1}$ Institute of Geological and Nuclear Sciences, Lower Hutt, New Zealand

${ }^{2}$ Member

${ }^{3}$ Fellow
}

results from blind prediction experiments at Turkey Flat [9] and Ashigara Valley [10]. The conclusion reached in their studies was that 2- and 3-dimensional models did not produce better results than 1-dimensional models even for a very complex site in Ashigara Valley, because of large uncertainty in site model parameters [10]. In the light of these experiments and also because of the essential 1-dimensional nature of the site analyzed in this paper (Gisborne Post Office site), a 1dimensional non-linear model was chosen.

Soil non-linear behaviour can be taken into account approximately by an equivalent linear approach [11] or "exactly" by a true non-linear approach [12]. Comparison of the results from both methods is presented in this paper.

Collecting geotechnical data for a soil site is very costly and is often limited by the capacity of available equipment. There is also a considerable amount of uncertainty in the data collected from laboratory and in-situ tests and the variability of geotechnical data must be considered. In this paper, a sensitivity study carried out on some of the geotechnical data is reported. 
Table 1: Main Geotechnical Test Results (from [13])

\begin{tabular}{|c|c|c|c|c|}
\hline Sample & Depth $(\mathrm{m})$ & $\begin{array}{c}\text { Plasticity } \\
\text { Index P.I. }\end{array}$ & $\begin{array}{c}\text { Bulk Density } \\
\left(\mathrm{kg} / \mathrm{m}^{3}\right)\end{array}$ & $\begin{array}{c}\text { Shear Strength } \\
(\mathrm{kPa})\end{array}$ \\
\hline $\mathrm{G}_{1}$ & 2.3 & 33 & 1875 & \\
\hline $\mathrm{G}_{2}$ & 4.5 & 38 & 1753 & 30.6 \\
\hline $\mathrm{G}_{3}$ & 6.6 & 36 & 1765 & 38.4 \\
\hline $\mathrm{G}_{4}$ & 8.3 & 40 & 1745 & 50.2 \\
\hline $\mathrm{G}_{5}$ & 10.4 & 55 & 1615 & 49.4 \\
\hline $\mathrm{G}_{6}$ & 11.9 & 64 & 1545 & 62.8 \\
\hline
\end{tabular}

Site amplification depends on both the strength of the bedrock excitation, because of soil non-linearity, and earthquake source and path effects, possibly affecting the frequency content of the excitation motion. These effects are investigated by selecting a suite of rock site motions from different earthquakes.

The Gisborne Post Office site has thick layers of soils with shear wave velocities ranging from $110 \mathrm{~m} / \mathrm{s}$ at the ground surface to $245 \mathrm{~m} / \mathrm{s}$ at a depth of $25 \mathrm{~m}$ according to the results of a seismic cone penetration test (SCPT) by Barker [7]. Six soil samples were taken from the site (at about a block away from the actual strong motion site) at depth of $1.7-12 \mathrm{~m}$ and the soil samples were tested by the Geotechnical Laboratory of Auckland University [13], with the main results summarized in Table 1. The most important parameters determined in the testing were the shear-modulus reduction and equivalent viscous damping ratios at various shear-strain amplitudes. The undrained shear strength was also obtained at the end of each experiment. The shear wave velocities of the samples at low strain amplitudes were measured by using Bender element tests and the measured velocities are reasonably consistent with the SCPT results, indicating that the sample disturbance is not too serious. The plasticity index increases from 33 at a $2 \mathrm{~m}$ depth to 64 at a $12 \mathrm{~m}$ depth. The soil samples were described [13] as soft dark grey clay and soft silty clay at depth range of $0-8 \mathrm{~m}$ and as firm dark grey silty clay at a depth about $12 \mathrm{~m}$.

The average shear-modulus reduction curves for the soil samples are quite different from those published results for similar plasticity indexes, as shown in Figure 1, where $G$ is the secant shear modulus, $G_{\max }$ is the shear modulus at small shearstrain amplitudes, and $\tau$ is the shear stress. For samples $G_{1}, G_{2}$ and $G_{3}$, the shear modulus reduction curves are very similar and the average $\mathrm{G} / \mathrm{G}_{\max }$ values at a shear strain amplitude less than $0.1 \%$ is smaller than the $\mathrm{C} 1$ model of Sun et al. [14] for clay with plasticity index 5-10, as shown in Figure 1(a). The plasticity index for samples $G_{1}, G_{2}$ and $G_{3}$ ranges from 33 to 38 , corresponding to those for the $\mathrm{C} 3$ model of Sun et al., but $\mathrm{G} / \mathrm{G}_{\max }$ of the $\mathrm{C} 3$ model is considerably greater than for the model fitted to the experimental data, as shown in Figure 1(a). The experimental data for samples $\mathrm{G}_{4}$ and $\mathrm{G}_{5}$ have similar variations to each other with shear-strain amplitude and their average $G / G_{\max }$ values are also significantly smaller than the $\mathrm{Cl}$ model for shear-strain amplitudes less than $0.1 \%$, as shown in
Figure 1(b). At strain amplitudes larger than $0.2 \%$, the average experimental results tend to be close to the $\mathrm{C} 3$ model for clays with plasticity indexes 20- 40 [14] (see Figures 1 (b) and 1(c)). The plasticity index for samples $G_{4}, G_{5}$ and $G_{6}$ ranges from 40 to 64 , corresponding to those for the $\mathrm{C} 4$ model by Sun et al. [14], but the $\mathrm{G} / \mathrm{G}_{\max }$ values of the $\mathrm{C} 4$ model are much greater than the models fitted to the experimental data. The maximum strain amplitudes for the tests are between $0.1-0.2 \%$ and all experimental results for strain amplitudes less than $0.2 \%$ lie below those of Sum et al. for the corresponding plasticity index.

For the Gisborne Post Office site, there is little information for soils at depth below $25 \mathrm{~m}$ and the description of the site condition at this depth was based on nearby borehole data with the depth to the bedrock being taken as $40 \mathrm{~m}$. The soil shear wave velocities from $25 \mathrm{~m}$ to $40 \mathrm{~m}$ depth were assumed to be between $245-345 \mathrm{~m} / \mathrm{s}$ so that this soil profile gives a low-strain site period of about $1.0 \mathrm{~s}$ and $1.0-1.2 \mathrm{~s}$ at moderate level of ground shaking, close to those observed from earthquake records. The shear wave velocity profile assumed for the site is given in Table 2.

There is a very large uncertainty for the shear wave velocity and mass density of the bedrock and it is very unlikely that a bedrock half space with a constant shear wave velocity would exist in a real situation. Shear wave velocity of bedrock is known to increase with depth even at a depth of a few kilometres and it is impractical to model such a depth for engineering site analyses. In this investigation we chose 1000 $\mathrm{m} / \mathrm{s}$ for the bedrock shear wave velocity and this approximately corresponds to Class B in the NEHRP recommendations [22, 34]. On the other hand, Zhao [17] shows that radiation damping, as a result of finite bedrock shear wave velocity, can be replaced by equivalent material damping and thus radiation damping will interact with the hysteresis damping from soil non-linear behaviour. A large amount of radiation damping will result in a small soil shear-strain amplitude and therefore a small amount of hysteresis damping and vice versa. This indicates that the amplification ratio estimated would not be very sensitive to a small change in the actual shear wave velocity used for the bedrock. 

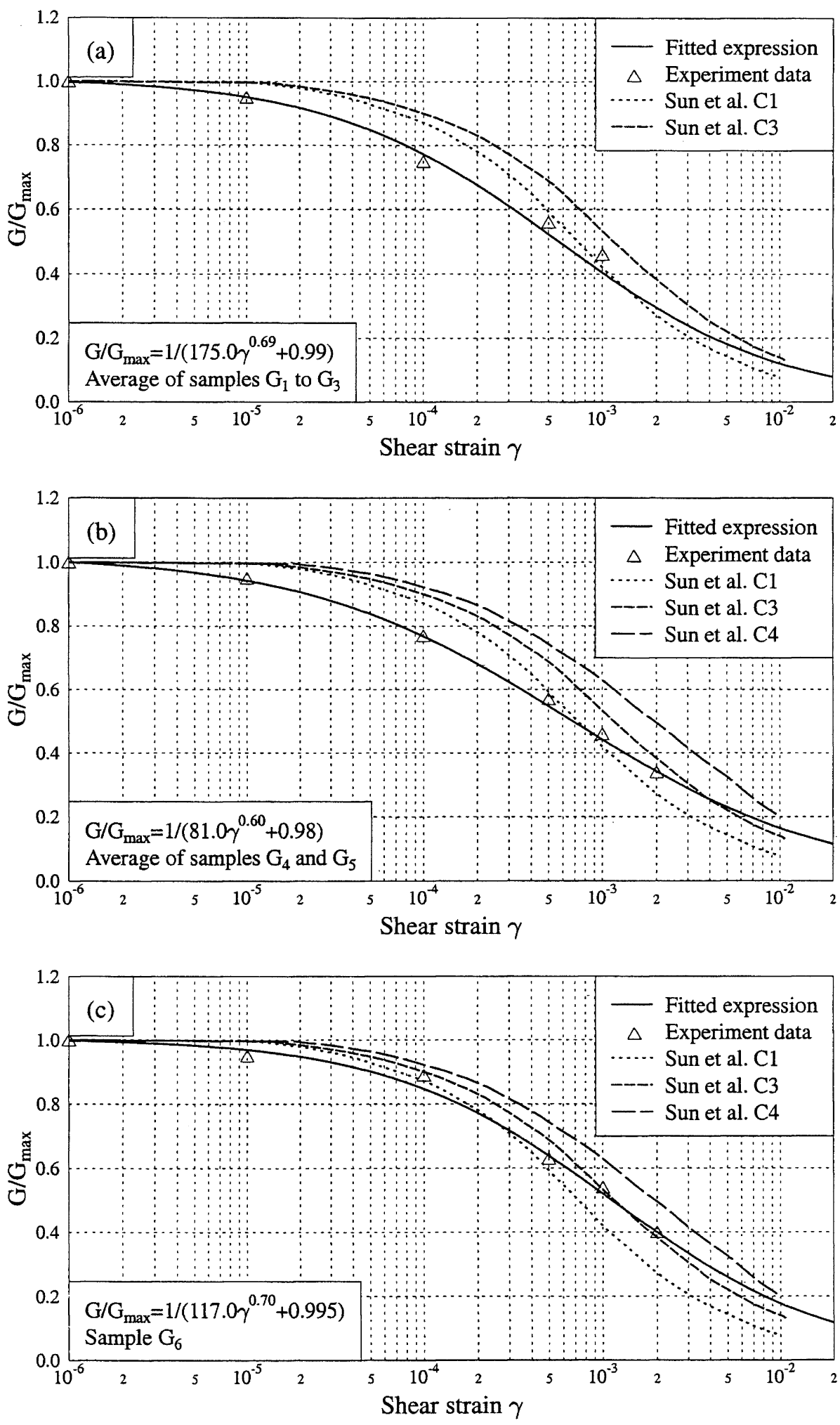

Figure 1: A non-linear model for soil samples from the Gisborne Post Office site, (a) at depth 0-7 m, (b) at depth 7-10 $m$ and (c) at depth $11.9 \mathrm{~m}$. The fitted expression was controlled by the experimental data as well as the undrained shear strength obtained from testing. The fitted expression and the data are compared with the C1, C3 and C4 models from Sun et al [14]. 
Table 2: Shear Wave Velocity Profile

\begin{tabular}{|c|c|c||}
\hline $\begin{array}{c}\text { Depth } \\
(\mathrm{m})\end{array}$ & $\begin{array}{c}\text { Density } \\
\left(\mathrm{kg} / \mathrm{m}^{3}\right)\end{array}$ & $\begin{array}{c}\text { Shear wave velocity } \\
(\mathrm{m} / \mathrm{s})^{*}\end{array}$ \\
\hline $0-10$ & 1750 & 111.6 \\
\hline $10-12$ & 1600 & 111.4 \\
\hline $12-20$ & 1600 & 129.3 \\
\hline $20-24$ & 1600 & 184.0 \\
\hline $24-32$ & 1600 & 245.0 \\
\hline $32-40$ & 1600 & $245.0(345.0)$ \\
\hline$\geq 40$ & 2000 & 1000. \\
\hline
\end{tabular}

* Based on SCPT measurements to $24 \mathrm{~m}$ depth and extrapolated at greater depths.

A total stress approach was used in the present study, implying an undrained condition for the soils. The non-linear computer program used was Densor [12] in which a series of elastoplastic elements was used to model the non-linear soil behaviour.

A suite of rock site records from moderate and large magnitude earthquakes was used as excitations for a plausible non-linear soil model established for the Gisborne Post Office site, to assess the variability associated with rock site motions. Amplification ratios will be presented for a limited number of spectral periods and these ratios will be used to demonstrate non-linear soil effects and to establish a site specific smoothed spectrum.

\section{EARTHQUAKE RECORDS OBTAINED FROM THE GISBORNE POST OFFICE SITE}

Gisborne Post Office is a 6-storey reinforced concrete momentresisting frame building, and the carpark (free-field) site is about $20 \mathrm{~m}$ away from the building. The building responses have been shown to exhibit reasonably strong soil-structure interaction [15], and contamination from the building base feed-back is expected to affect the carpark site records to a small extent.

Two complete sets of earthquake records were obtained in earthquakes in 1982 and 1993. The 1982 earthquake had a local magnitude of 5.1 and an assigned depth of $33 \mathrm{~km}$. The epicentral distance to the Gisborne Post Office was $25 \mathrm{~km}$. A horizontal peak ground acceleration (PGA) of $0.06 \mathrm{~g}$ was recorded at the carpark site. The 1993 (Ormond) earthquake was centred at an epicentral distance of $23 \mathrm{~km}$ from the Gisborne Post Office and had a moment magnitude of 6.2 and a focal depth of $48 \mathrm{~km}$. A horizontal PGA of $0.26 \mathrm{~g}$ was recorded at the carpark site and this record is the largest record from a deep soft soil site in New Zealand.
Unfortunately, there was no working instrument on a nearby rock site during these earthquakes. It is a difficult task to find a rock site close to the city. A digital instrument was installed on the top of Kaiti Hill in 1991 in an attempt to obtain rock site records for possible modelling work for the soil sites in Gisborne. A record was obtained from this digital instrument in the 1993 Ormond earthquake, but the analysis of the record revealed that possible topographical effect and a soil layer on the hill top site significantly modified the ground motions in a frequency band around $2 \mathrm{~Hz}$. These modifications mean that the hill site record could not be used as a reasonable representative of the bedrock outcrop motions in computer modelling of the soil site reported here.

\section{INFLUENCES OF SOIL PARAMETERS}

Influences of soil shear strength:

The experimental results show that the undrained shear strength is similar for samples 2 and 3 (not available for sample 1) and is also similar for samples 4 and 5. A model can be established for the soils at depth of $0-7 \mathrm{~m}$ by using the average shearmodulus reduction curve for soil samples 1-3, as shown in Figure 1(a). For the soils at depth $7-10 \mathrm{~m}$, the average of the experimental data for samples 4 and 5 as shown in Figure 1(b) can be used, and for the soils at depth 10-20 m the experimental data from soil sample 6, as shown in Figure 1(c), can be used. The ratio of the mean measured undrained shear strength to the maximum measured shear modulus, $\tau_{s} / G_{\max }$, was used as a constraint in establishing the soil non-linear models. The shear-strain amplitude at which the shear strength was reached was unknown and $2 \%$ was assumed here based on the triaxial testing for soil samples from another site [16]. The modulus reduction curve was assumed to be a function of shear strain of the form $G / G_{\max }=1 /\left(a \gamma^{n}+b\right)$, with the parameters determined by the best fitting by eye of the average experimental data and the specified shear strength. The non-linear soil model using the fitted shear modulus reduction curves shown in Figure 1 is referred to as model 1 hereafter.

For surface layers, it is possible that the soil shear strength is reached at a strain amplitude much smaller than $2 \%$ as specified because the maximum strain amplitude of the soil experiments was only $0.2 \%$. To investigate this effect, the nonlinear model was modified for the soils at depth $0-7 \mathrm{~m}$ so that the undrained shear strength was reached at a shear strain amplitude about $1 \%$, as shown in Figure 2(a). Non-linear models from Figures 2(b) and 2(c) were used for the other layers. This model is referred to as model 2. The non-linear model shown in Figure 2(a) seems to fit the experimental data better than the model given in Figure 1(a).

In specifying the non-linear soil models for large shear strain amplitudes, very large extrapolation is required and two nonlinear models can have very similar goodness of fit to the experimental data but give quite different levels of shear strength. For example, the non-linear model shown in Figure 2(b) for the soil layer at depth 10-20 m gives a shear strength about $2 / 3$ of that shown in Figure 1(c). Model 3 was established by using the non-linear model shown in Figure 2(a) for soil layers at depth of 0-7 m, those in Figure 1(b) for soil layers at depth 7-10 $\mathrm{m}$ and that in Figure 2(b) for soil layers at $10-20 \mathrm{~m}$. 

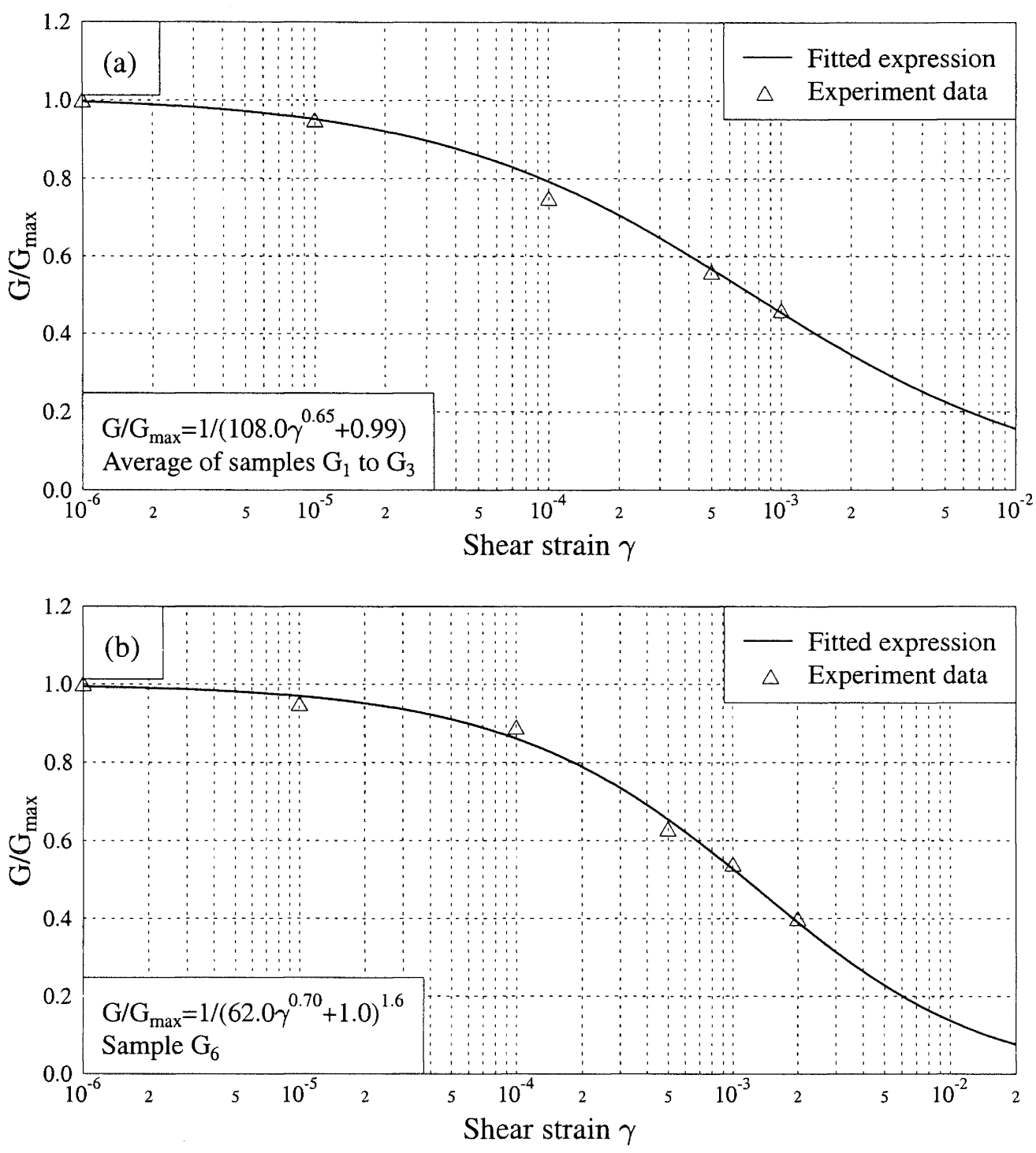

Figure 2: Alternative non-linear models (a) for data shown in Figure 1(a) with the shear strain at which the undrained shear strength reaches being reduced to 0.01 , and (b) fitted to the experimental data for soil sample $G_{6}$ but the shear stress at a shear strain amplitude of 0.02 is much reduced from the experimental data.

A non-linear soil model corresponding to the $\mathrm{C} 3$ curve of Sun et al. [14] and a shear wave velocity of $245 \mathrm{~m} / \mathrm{s}$ was used for the soil layers at depth between $20-40 \mathrm{~m}$ for all three models.

For earthquakes that generated records at the Gisborne Post Office site there were no rock site records available, either nearby or at distance. A record obtained from Maraenui Primary School site in the 1993 Ormond earthquake was considered, because this record contains the same source effect as that at the Gisborne Post Office site. This site has, however, a thin layer of soil over bedrock [6] and the ground motion is noticeably amplified at $0.2-0.25$ seconds. This site is located in the $\mathrm{N} 23 \mathrm{E}$ direction with respect to the epicentre of the earthquake. The Gisborne Post Office site is located in the S27E direction with respect to the epicentre, almost in the opposite sites to the Maraenui site with respect to the epicentre. The different site locations relative to the earthquake source would likely result in different ground motion characteristics at these two sites. The mean PGA of the two horizontal components for the Maraenui record is only $0.09 \mathrm{~g}$. This record was used as one of the input motions for the present study. 

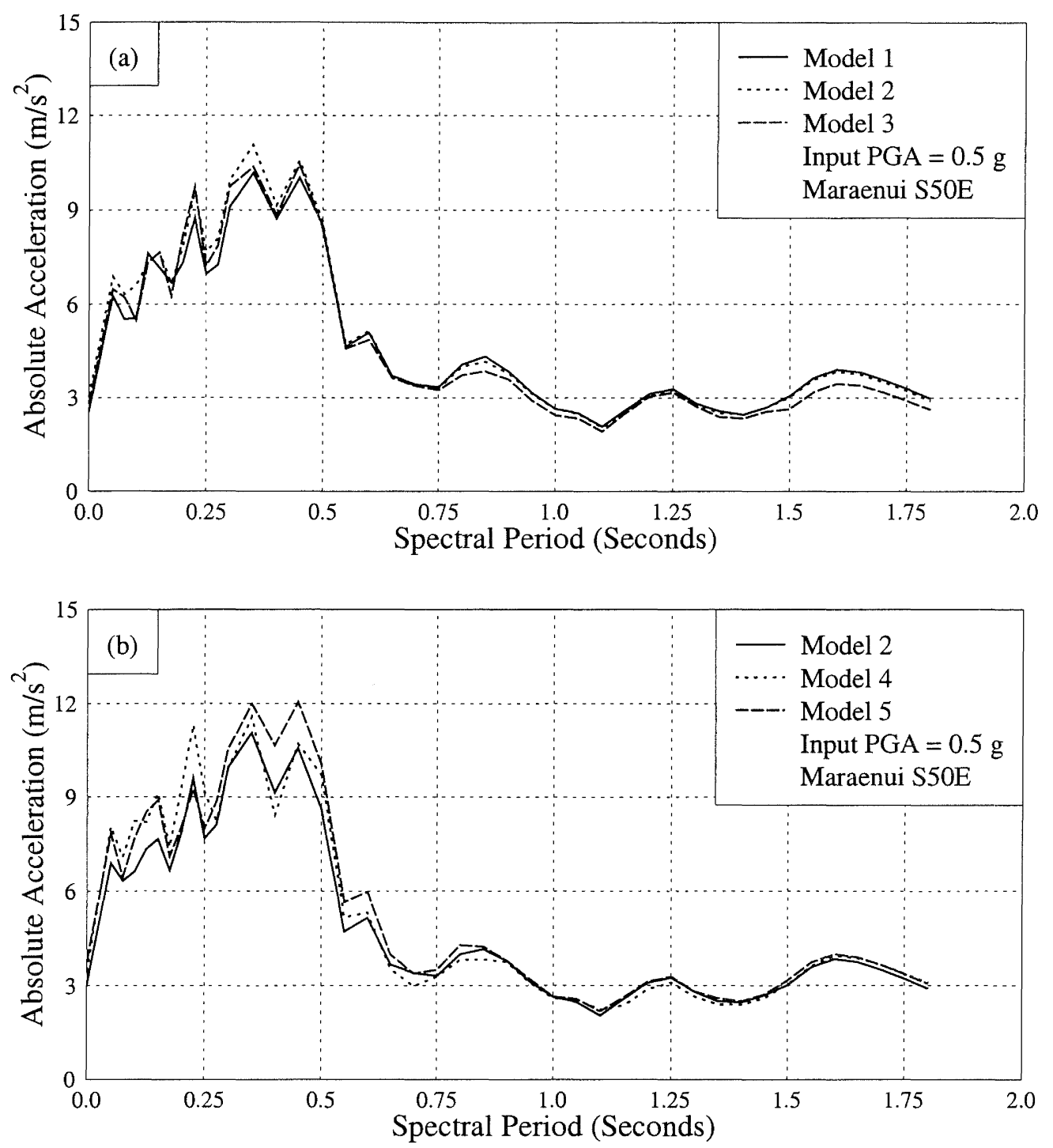

Figure 3: Response spectra computed from various possible non-linear soil models subjected to the Maraenui record (S50E) from the 1993 Ormond earthquake scaled to give a PGA of $0.5 \mathrm{~g}$, (a) comparison for models 1,2 and 3, and (b) comparison for models 2,4 and 5.

The response spectra for models 1,2 and 3 are shown in Figures 3(a) for the Maraenui excitation scaled to a PGA of $0.5 \mathrm{~g}$, with the three models producing practically the same site surface response spectra. The response spectra for the three models were very similar to each other for the excitation scaled to a PGA of $1.0 \mathrm{~g}$ and almost identical to each other for the excitation scaled to a PGA of $0.2 \mathrm{~g}$. The change of strain amplitude at which the surface layers (0-7 $\mathrm{m}$ depth) reach their maximum shear strength and the reduction in the shear strength of the soil layers at 10-20 m depth make little differences at all periods even for a very large amplitude of excitation. This is expected because the maximum shear strain developed anywhere in the soil was typically $0.5 \%$ for large bedrock excitations. The stress decrease, due to either the reduction of shear strain at maximum shear strength or reduction in shear strength, at this level of strain amplitude can be compensated by a small increase in the maximum strain developed in the soil layer.

(b) Effects of soil properties of the bottom layers:

There is a large uncertainty in determining the shear wave velocities and the non-linear models for the soil layers below $25 \mathrm{~m}$ because there were no direct measurements available. The effect of these uncertainties is investigated here.

In model 4 , the soils at depth of $32-40 \mathrm{~m}$ were taken as a separate layer with shear wave velocity increasing from 245 $\mathrm{m} / \mathrm{s}$ to an arbitrary value of $345 \mathrm{~m} / \mathrm{s}$ while the material properties for all the other layers were the same as for model 2 . 
In model 5 , the non-linear clay models used for the soil at depths of $24-40 \mathrm{~m}$ were changed from the $\mathrm{C} 3$ to the $\mathrm{C} 4$ model of Sun et al. [14], using the same non-linear models as for model 2 for all the other layers.

The response spectra of models 2, 4 and 5 are compared in Figure 3(b) for an excitation with a PGA of $0.5 \mathrm{~g}$. The differences between these models at periods longer than $0.6 \mathrm{~s}$ are very small for all levels of bedrock excitation, and the change of non-linear model for the bottom layer increases the response spectra with respect to model 2 only moderately at short periods (less than $0.6 \mathrm{~s}$ ) for all levels of bedrock shaking.

Effect of a thin layer of soil on the reference rock site:

As described earlier, the Maraenui site is likely to have a layer of soil over bedrock [6] and the response spectrum of the Ormond earthquake record has a sharp peak at $0.2-0.25 \mathrm{~s}$, the same period at which a peak exists in a few other records from this site. The effect of a thin soil layer can be corrected approximately by a simple response function for a uniform layer of soil on an elastic half space. If material damping is neglected, the correction factor is a function of layer natural period and the impedance contrast [17], $p=\rho_{R} v_{R} / \rho_{L} v_{L}$, where $\rho$ and $\mathrm{v}$ denote mass density and shear wave velocity respectively and subscripts $\mathrm{R}$ and $\mathrm{L}$ denote half space and the soil layer respectively. If the natural period of Maraenui site is taken as $0.23 \mathrm{~s}$, the correction factor is given in Figure 4(a) for various values of $\mathrm{p}$. In this model, the only source of damping is from radiation into the half space, with lower values of $p$ giving greater damping. A small value of $p$ can be selected to account for the effect of material damping, with an advantage of using radiation damping to replace material damping being that highfrequency noise present in the record will not be amplified. The modified Maraenui records corresponding to the selected value of $\mathrm{p}=2$ have much smaller PGAs than the original records: reducing from $0.08 \mathrm{~g}$ to $0.05 \mathrm{~g}$ for the $\mathrm{S} 50 \mathrm{E}$ component and from $0.11 \mathrm{~g}$ to $0.063 \mathrm{~g}$ for the $\mathrm{N} 40 \mathrm{E}$ component.

Figure 4(b) shows the response spectra for the original and modified S50E component of the Maraenui record and it can be seen that the long period portion of the record is virtually unchanged. Figure 4(c) shows that the original and modified records (unscaled) produce very similar spectral values at long periods $(>0.7 \mathrm{~s})$ but the difference at short period is significant, as expected.

\section{COMPARISON OF CALCULATED AND RECORDED MOTION AT THE GISBORNE POST OFFICE SITE}

It is difficult to make a direct comparison between the calculated and the recorded soil site motions here because there is no record available from a nearby rock site. Bedrock motions can be derived from ground surface motions by using an equivalent linear approach such as that of the SHAKE program [11]. This method would serve no useful purpose for the present study, as the aim of the present study is to use the limited amount of site material information and recorded ground motions to establish a credible site soil profile and nonlinear model, so that ground motions during severe ground shaking can be estimated. An alternative approach to estimate the possible bedrock ground motions is adopted here. The mean PGA of the two horizontal components at the Gisborne Post Office site in the 1993 Ormond earthquake was $0.22 \mathrm{~g}$ and the mean soil site PGA factor in a recently developed New Zealand PGA attenuation model is 1.53 [18]. The possible mean PGA in the 1993 Ormond earthquake for a rock site close to Gisborne Post Office site would thus be close to $0.14 \mathrm{~g}$. A suite of rock site records from earthquakes with similar magnitudes (and if possible similar distances, if such records can be found) scaled to have a mean PGA of $0.14 \mathrm{~g}$ can be used as bedrock motions for the soil model. If the calculated ground surface motions have a mean response spectrum similar to that of the recorded motions, we can suggest that the soil model established would be appropriate, and can be used to predict large ground motions, with various soil parameters that affect the ground motion for a large bedrock excitation being investigated within a credible range.

Scaled version of the original and modified Maraenui record from the 1993 Ormond earthquake are possible candidates for the rock site motions. These records would contain the same source effect as the record at the Gisborne Post Office site. The calculated mean response spectra at Gisborne Post Office site using the $0.14 \mathrm{~g}$ PGA scaling of the original and the modified Maraenui record as excitations are compared with the mean spectra of the recorded motion in Figure 5. Figure 5(a) shows that the calculated mean acceleration spectrum at long periods using the Maraenui records is considerably less than the mean recorded spectrum, because of relatively strong high frequency components in the input motion, while at the short periods the two mean spectra are similar. The recorded spectral peaks at about $0.3 \mathrm{~s}, 0.6 \mathrm{~s}$ and $1.1 \mathrm{~s}$ are not produced by the model either and this discrepancy is possibly caused by the lack of strong components at these periods in the Maraenui record as shown in Figure 4(b), because of different path effect at the Maraenui and the Gisborne sites (in almost opposite directions with respect to the earthquake source). Figure 5(a) also shows that the mean response spectrum calculated from the modified Maraenui record compares reasonably well with the mean recorded spectrum at the Gisborne Post Office site at both short and long periods. Figure 5(b) shows the mean displacement response spectrum calculated from the two bedrock motions compared with the mean spectrum of the record. The mean spectrum of the ground motions generated by the modified Maraenui record matches the mean recorded one reasonably well, though the peak at $1.1 \mathrm{~s}$ was not produced possibly because of lack of strong components at this period as shown in Figure 4(b). The discrepancy at $1.1 \mathrm{~s}$ can be attributed to the possible different path effects on the two sites, and the discrepancy is smaller than that in the spectrum generated by the original record. The predicted site period between $1.1-1.2 \mathrm{~s}$ will be demonstrated in the spectral ratios in the later section. The good match indicates that the non-linear model (model 2) for the Gisborne Post Office site is plausible. It can be noted that the mean calculated PGAs are slightly smaller than the mean recorded PGAs, suggesting that the soil site factor of 1.53 is possibly too large, perhaps because the attenuation model does not account for non-linear effects in the soil (use of a constant soil site factor). If a smaller soil site factor was used, resulting in larger scale factors and a larger PGA (for example $0.2 \mathrm{~g}$ ) than those shown in Figure 5(a), a slightly better match may be expected. 

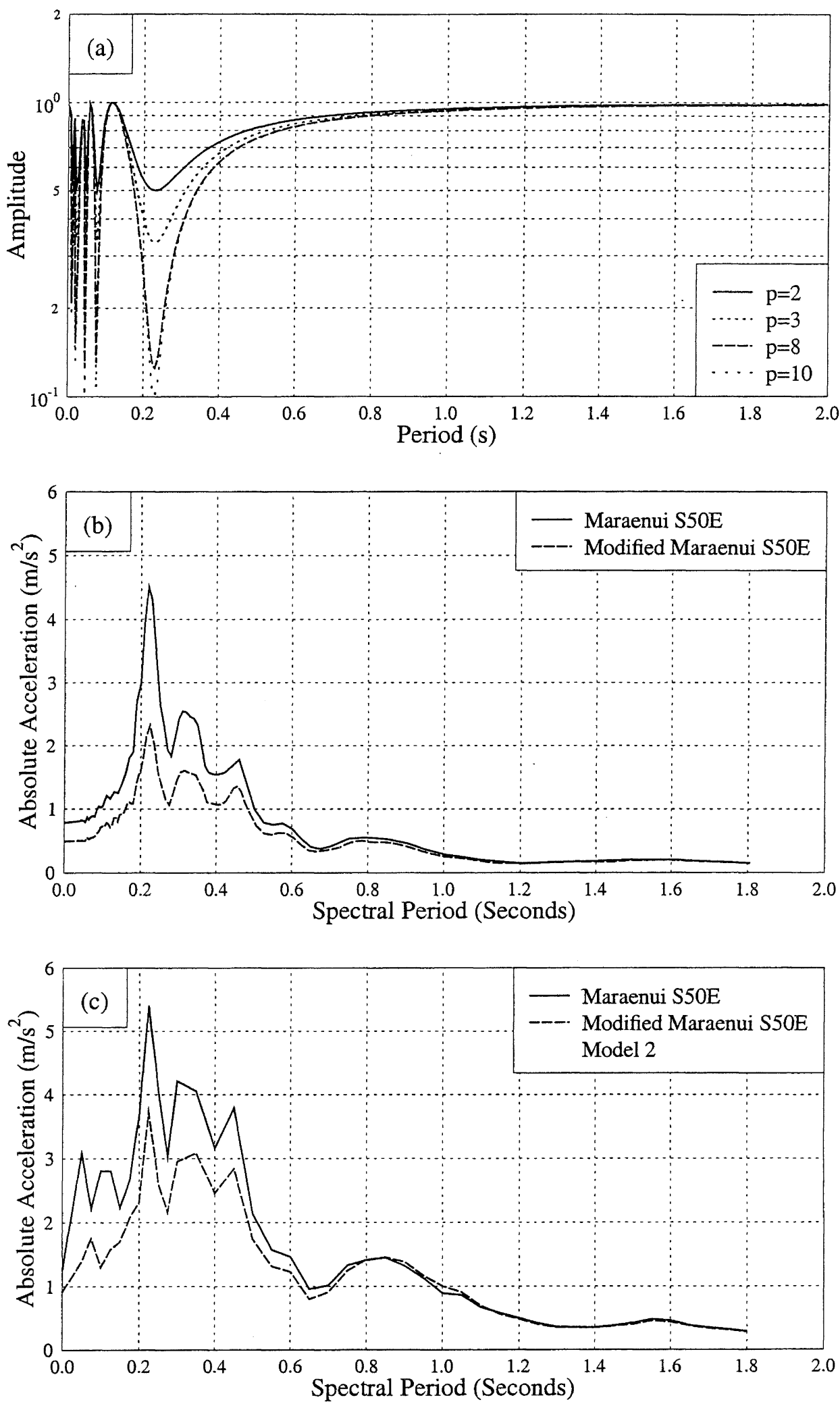

Figure 4: $\quad$ Effect of a thin layer of soil in reference rock site, (a) Fourier spectral ratios for a single soil layer on an elastic half space, (b) response spectra for the original and modified version of S50E component of the Maraenui record, and (c) the response spectra from non-linear soil model subjected to Maraenui record and the modified version by the Fourier spectral ratio shown in (a). 

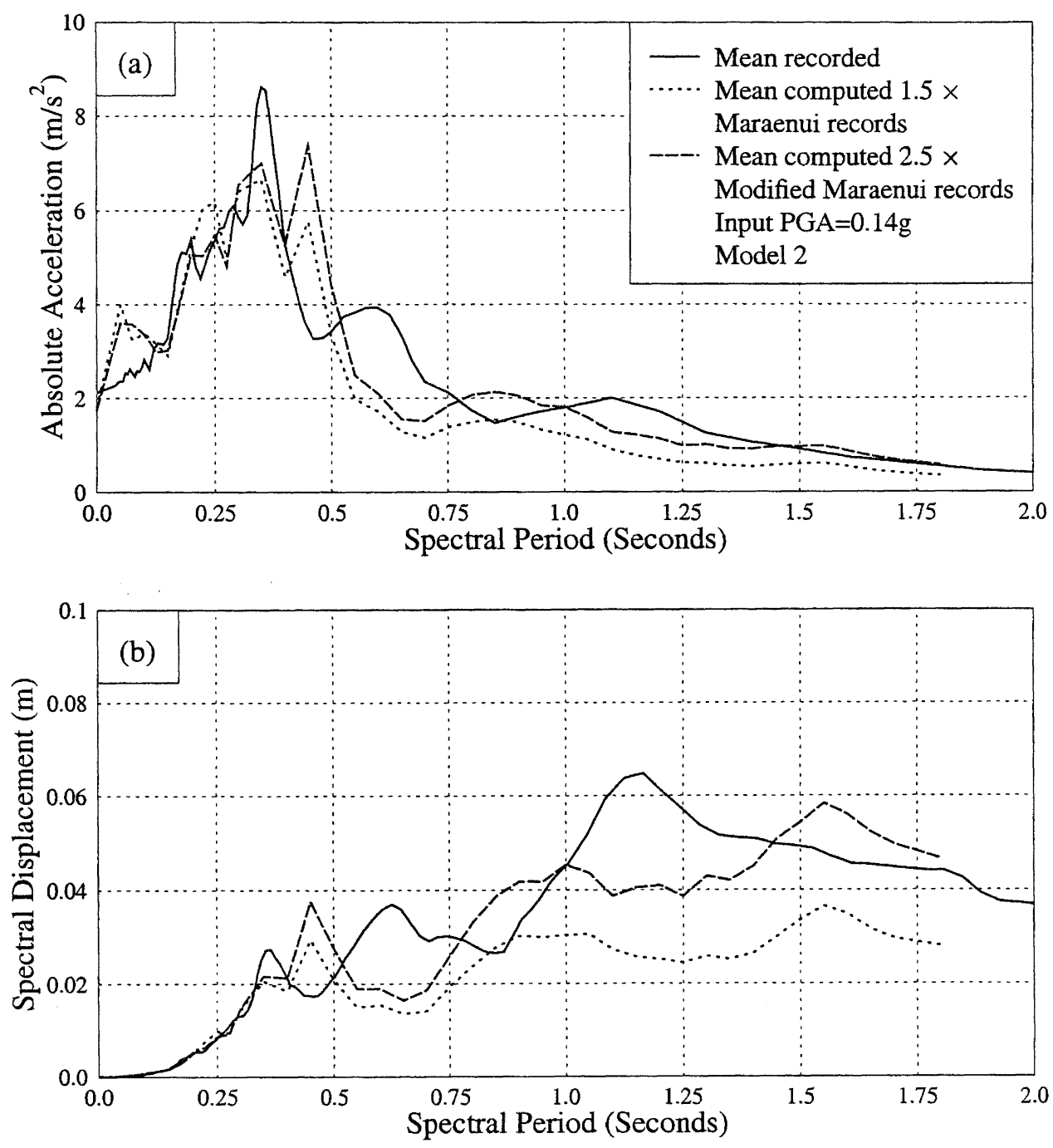

Figure 5: Comparison of the mean recorded and the mean computed response spectra for the Gisborne Post Office site, (a) acceleration spectra, and (b) displacement spectra.

\section{SITE AMPLIFICATION ESTIMATED FOR THE GISBORNE POST OFFICE SITE}

It was shown in the previous sections that the response of the non-linear soil model was not very sensitive to the selection of the soil site material parameters within a creditable range and that model 2 was plausible for the site. To estimate site amplification, a suite of rock site motions has to be selected, so that the effects of frequency content of bedrock excitations due to source, path and site conditions of the rock stations (for example, soft rock, hard rock etc., usually very poorly defined) can be approximately accounted for.

Two New Zealand rock sites selected here are Te Kuha and Maraenui (with a thin layer of stiff soil) sites. Te Kuha on the west coast of South Island is on a hard rock outcrop (quartz diorite) [6]. The Paparoa Event 1 and Event 2 with moment magnitudes of 5.8 and 5.9 generated two sets of records respectively. The closest distance to the source rupture from the site was about $13 \mathrm{~km}$ for both events and the PGA was
$0.21 \mathrm{~g}$ in event 1 and $0.13 \mathrm{~g}$ in event 2 . The Te Kuha records and the Maraenui records (and the modified version) from the 1993 Ormond earthquake were scaled to have PGAs from $0.05 \mathrm{~g}$ to $1.0 \mathrm{~g}$ as excitations for the model.

Rock site records from the 1989 Loma Prieta earthquake $\left(M_{w}=6.9\right)$ and the 1994 Northridge earthquake $\left(M_{w}=6.7\right)$ were also selected as excitations for the model, with the station names and available information for site conditions given in Tables 3 and 4 . The site conditions were obtained from Boore et al. $[19,20]$ and Chin \& Aki [21] for the Loma Prieta earthquake, and Chang et al. [23] and Crouse \& McGuire [22] for the Northridge earthquake. Boore et al. $[19,20]$ presented the average shear wave velocity of the top $30 \mathrm{~m}$ of a site while the other authors presented only site descriptions or classifications. Station topography is not generally available but Chang et al. [23] discussed the possible strong topographical effect at the Castaic - Old Ridge Route site, the only site which was excluded from 
Table 3: Information about Rock Site Records from the 1989 Loma Prieta Earthquake

\begin{tabular}{||l|l|l|}
\hline $\begin{array}{c}\text { Source Distance } \\
(\mathrm{km})\end{array}$ & Station Name & Site condition \\
\hline 19.9 & ST 3: Santa Cruz-UCSC/Lick Lab. & Limestone \\
\hline 30.8 & ST15: Gilroy 1-Gavilan College, Water Tank & Franciscan sandstone \\
\hline 50.2 & ST37: Monterey-City Hall & Granite \\
\hline 54.9 & ST35: Sago South-Hollister, Cienega Rd. & Granite \\
\hline 63.7 & ST39: Upper Crystal Spring Res. -Skyline & Sandstone \\
\hline 71.5 & ST45: Hayward-CSUH Stadium Grounds & Franciscan greenstone \\
\hline 95.6 & ST 8: San Francisco-Rincon Hill & Franciscan sandstone \\
\hline 96.3 & ST 6: Yerba Buena Island & Franciscan sandstone \\
\hline 97.3 & ST10: San Francisco-Pacific Heights & Franciscan sandstone \\
\hline 97.4 & ST 9: San Francisco-Telegraph Hill & Franciscan sandstone \\
\hline 100.1 & ST12: San Francisco-Cliff House & Franciscan sandstone \\
\hline 104.2 & ST42: Point Bonita & Sandstone \\
\hline
\end{tabular}

Table 4: Information about Rock Site Records from the 1994 Northridge Earthquake

\begin{tabular}{||l|l|l||}
\hline $\begin{array}{c}\text { Source Distance } \\
(\mathrm{km})\end{array}$ & Station Name & Site condition \\
\hline 23.6 & Topanga Fire Station & Rock $^{1}$ \\
\hline 24.4 & LA Griffith Observatory & $\mathrm{A}^{1}$ \\
\hline 27.0 & Malibu Canyon - Monte Nido Fire Station & Rock \\
\hline 28.4 & Lake Hughes \#9 & A \\
\hline 32.1 & LA - Temple and Hope & Rock \\
\hline 34.0 & Lake Hughes \#4 & A \\
\hline 36.9 & Mt. Wilson - Caltech Seismic Station & A \\
\hline 37.1 & LA - City Terrace & Rock \\
\hline 38.6 & Leona Valley \#1 & Rock \\
\hline 38.7 & Leona Valley \#3 & Rock \\
\hline 45.7 & Point Mugu - Laguna Peak & Rock \\
\hline 47.9 & Littlerock - Brainard Canyon & Rock \\
\hline 50.8 & Rolling Hills Estates - Rancho Vista School & Rock \\
\hline 51.7 & Palos Verdes Reservoir Abutment Building & Rock \\
\hline 69.7 & Carbon Canyon Dam Right Abutment & Rock \\
\hline 70.3 & Carbon Canyon Dam Left Abutment & Rock \\
\hline 90.9 & San Joaquin Reservoir Left Abutment & Rock \\
\hline
\end{tabular}

Notes: $\quad 1$ Site classification given by Chang et al. [23].

2 Rock site classification given by Crouse and McGuire [22] 
their data set because of topographical effects. The topographical effect is not considered to be very large considering many other variabilities, for example, site shear wave velocities. These records were used without being scaled.

Spectral shapes for records from earthquakes with a moderate difference in magnitudes are very different as shown in Figure 6. The difference in spectral shape in the two horizontal directions from the same set of records is also quite large, as shown in Figure 9(a). Most records selected from the 1989 Loma Prieta earthquake have relatively large spectral values in the period band of $0.5-1.0 \mathrm{~s}$.

As expected, the response spectral ratios between the surface motion of the model and the input excitation are strongly affected by soil non-linearity and their variation is very large. For example, the ratio of the ground surface PGA and the PGA of the input varies from 0.6 to about 3 for the Loma Prieta earthquake records. In order to show the non-linear effect, spectral ratios are presented as a function of the excitation spectral value for a particular period in Figures 7-10. It can be seen that the spectral value of the excitation at a particular period has a first order effect on the spectral ratio of that period. The scatter is largely caused by the different frequency content of the records, i.e., different shapes of the normalized spectra. This can be confirmed by the fact that, if a single record is scaled to give different amplitude inputs, the scatter in the amplification ratios, as a function of rock site input spectral values, is negligible.

In a recent attenuation model for acceleration response spectra, non-linear site response effects have been recognized [24] and accounted for in the model development. Abrahamson and Silva [24] described the non-linear soil behaviour by having spectral ratios as a function of rock site PGA. The limited amount of simulation carried out in this paper shows that the spectral ratio is better taken as a function of rock site spectral values at the same spectral period rather than of rock PGA. Figure 9(a), where spectral ratios are plotted as functions of rock site spectral values at $0.75 \mathrm{~s}$, shows a much smaller scatter than that in Figure 11(a), where the spectral ratios are plotted as functions of rock site PGAs. This is also generally the case for all other periods. However, such a reduction in scatter for ratios of recorded soil and rock site motions is likely to be much smaller or even insignificant, because many other variabilities and uncertainties would diminish such kind of improvement in the scatter.

We attempted to fit the simulated data with a simple analytical function to describe the first order effect in amplification ratios. The functional form of Abrahamson and Silva [24] was used here, i.e.

$$
\ln (\mathrm{SR})=\mathrm{a} \cdot \ln \left(\mathrm{SA}_{\mathrm{r}}+\mathrm{c}\right)+\mathrm{b}
$$

where SR denotes spectral ratio and $\mathrm{SA}_{\mathrm{r}}$ is the rock site spectral value. Soil site spectrum can be calculated by $\mathrm{SA}_{\mathrm{s}}=\mathrm{SA}_{\mathrm{r}} \mathrm{SR}$. The constants $\mathrm{a}, \mathrm{b}$ and $\mathrm{c}$ can be determined by regression for each period. For long periods, i.e., 2.0 and 2.5 seconds, c $=$ 0.03 was chosen so that the extrapolation to a large rock site spectral value would not give too large a spectral ratio. For $0.5 \mathrm{~s}$ and $1.25 \mathrm{~s}$ periods, the regression produced $\mathrm{a}<-1.0$ and this value of a means that $\mathrm{SA}_{\mathrm{s}}=0$ when $\mathrm{SA}_{\mathrm{r}}=\infty$, clearly not physically logical. For these two periods, $\mathrm{a}=-1.0$ was selected Because the correlation is quite significant between a and $c$ and between $b$ and $c$, a predefined a has little effect on the standard error of the model prediction and the mean-ratio prediction. The data obtained by using the Maraenui and the Te Kuha records for 2.0 and 2.5 seconds were not included as the high pass filter limit in the record processing was just below $2.0 \mathrm{~s}$. The regression constants and the standard error are summarized in Table 5. The standard errors are in the range of 0.12- 0.22 , corresponding to factors of 1.13-1.25.

Table 5: Regression Coefficients for Spectral Ratios

\begin{tabular}{||l|l|l|l|l||}
\hline $\mathrm{T}$ & $\mathrm{a}$ & $\mathrm{b}$ & $\mathrm{c}$ & $\sigma$ \\
\hline 0.0 & -0.827 & -1.056 & 0.064 & 0.207 \\
\hline 0.1 & -0.773 & -0.613 & 0.065 & 0.221 \\
\hline 0.2 & -0.799 & -0.235 & 0.282 & 0.149 \\
\hline 0.3 & -0.976 & 0.219 & 0.586 & 0.178 \\
\hline 0.4 & -0.936 & 0.173 & 0.406 & 0.165 \\
\hline 0.5 & -1.000 & 0.377 & 0.632 & 0.155 \\
\hline 0.75 & -0.376 & -0.120 & 0.012 & 0.119 \\
\hline 1.0 & -0.633 & -0.134 & 0.070 & 0.182 \\
\hline 1.25 & -1.000 & 0.215 & 0.355 & 0.202 \\
\hline 1.5 & -0.940 & 1.03 & 0.999 & 0.191 \\
\hline 2.0 & 0.154 & 1.11 & 0.030 & 0.183 \\
\hline 2.5 & 0.081 & 0.775 & 0.030 & 0.211 \\
\hline
\end{tabular}

Figure 7(a) shows the PGA ratio as a function of rock site PGA and the fitted expression is also shown in Figure 11(b) in terms soil site PGA versus rock site PGA. The cross over point for the mean curve corresponds to $0.22 \mathrm{~g}$, and the cross over points for "mean $\pm \sigma$ " curves are $0.15 \mathrm{~g}$ and $0.29 \mathrm{~g}$ respectively. Figure 11(b) also shows that the probability of the surface PGA of this soil model exceeding $0.4 \mathrm{~g}$ would not be very large even for a rock motion with a PGA close to $1.0 \mathrm{~g}$. These features will be discussed further in this paper. Figure 7 shows that at short periods, rock site records generated by small magnitude earthquakes, such as the Te Kuha records, will produce smaller spectral ratios than the rock site records from large magnitude earthquakes, such as the Loma Prieta records, presumably because of lack of long period (close to the site elastic period) motion in the rock site records from a small magnitude event. It is possible that for a small magnitude earthquake, the amplification ratio for short period would be close to the "mean $-\sigma "$ curve, and for a large magnitude earthquake the amplification ratio would be close to the "mean $+\sigma$ " curve Different PGA amplification curves for small and large magnitude earthquakes were suggested by Idriss [25] and Dickenson and Seed [26]. For periods longer than $0.3 \mathrm{~s}$, the effect of earthquake magnitude for this limited simulation is not obvious, as shown in Figures 8-10(a). 

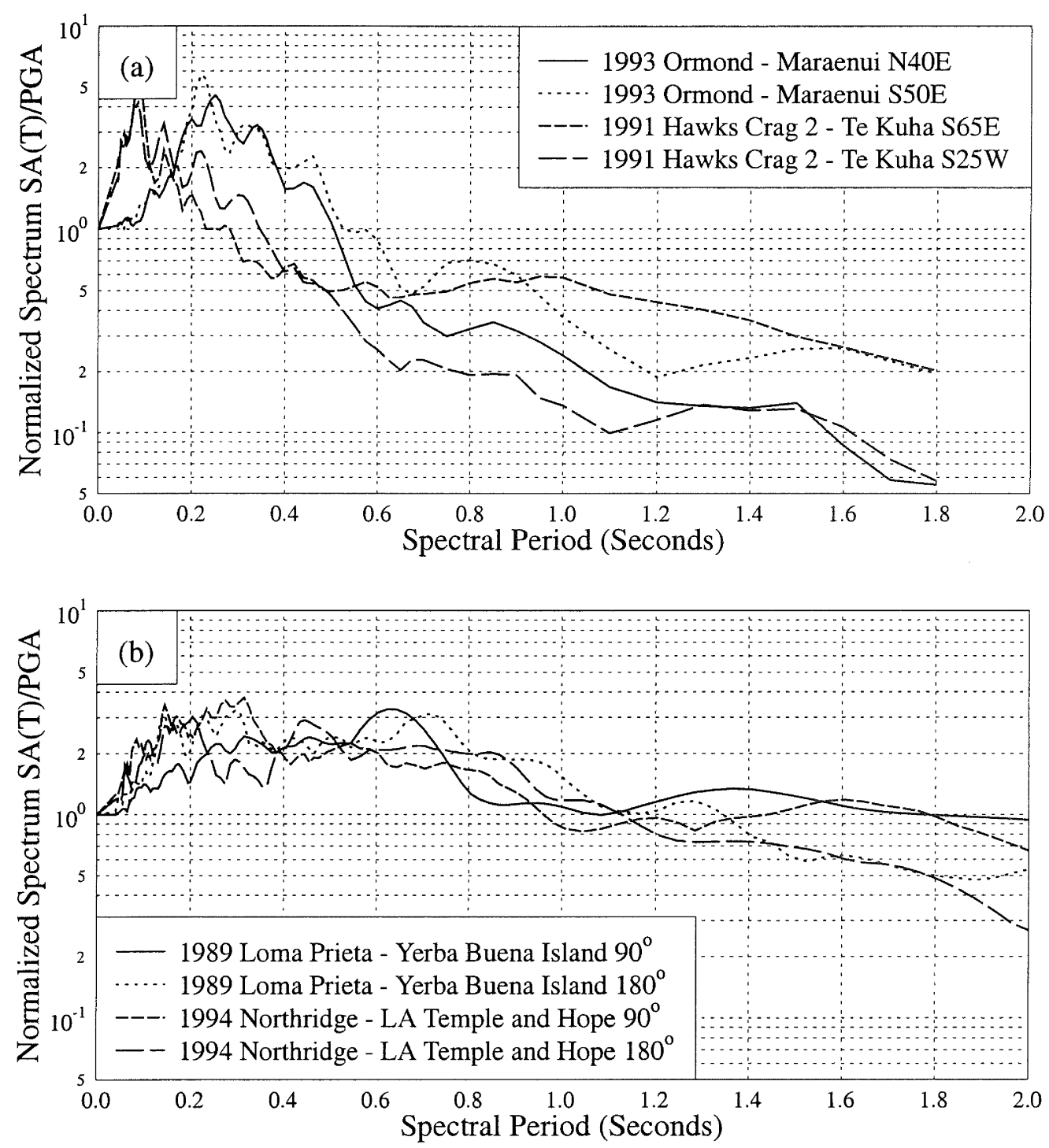

Figure 6: Normalized spectra for some of rock site records used as bedrock excitations for the non-linear model, (a) records from small-moderate magnitude earthquakes, and (b) records from large magnitude earthquakes.

Deamplification period range, in which the soil site will deamplify the input response spectra, exists within the range of simulation, up to the site elastic period of 1.0s. At 1.25 and $1.5 \mathrm{~s}$, the trend of variation seems to suggest that the amplification ratio decreases with the increase of input spectral values, as shown in Figures 9(c) and 10(a). The scatter is relatively large at periods 1.0 second or larger compared with short periods from $0.2-0.75 \mathrm{~s}$, possibly because of the shifting of "apparent" fundamental modal period, at which the Fourier spectral ratio between the model surface motion and the input bedrock motion has a dominant peak, due to soil nonlinearities. The scatter generally increases with the increase of periods from $0.75 \mathrm{~s}$.

It is interesting to note that at spectral periods of 2.0 and 2.5 seconds, the amplification ratios increase with the increase of input spectral amplitudes, in contrast to the other periods. The attenuation model by Abrahamson and Silva [24] also gives increasing spectral ratios with the increase of rock site PGAs at periods longer than 1.0s. The change in the mean amplification ratio due to the change of rock site spectral values within the range of the simulated data shown in Figures 10(b) and (c) is smaller than the range of mean and "mean $+\sigma$ " curves. The possible explanation for the increase of amplification ratios is that the rock site records with long period ( 2.0 and 2.5 seconds) spectral values tend to have relatively strong motions at the "apparent" site fundamental modal period compared with the other periods and the large amplification at the long periods is somehow a "feed through" by the "apparent" fundamental mode. If a single record is scaled to give various levels of input, the amplification ratios at 2.0 and 2.5 seconds are virtually constant. Soil non-linearity does not seem to have any effect on the amplification at periods much longer than the site elastic first modal period. 

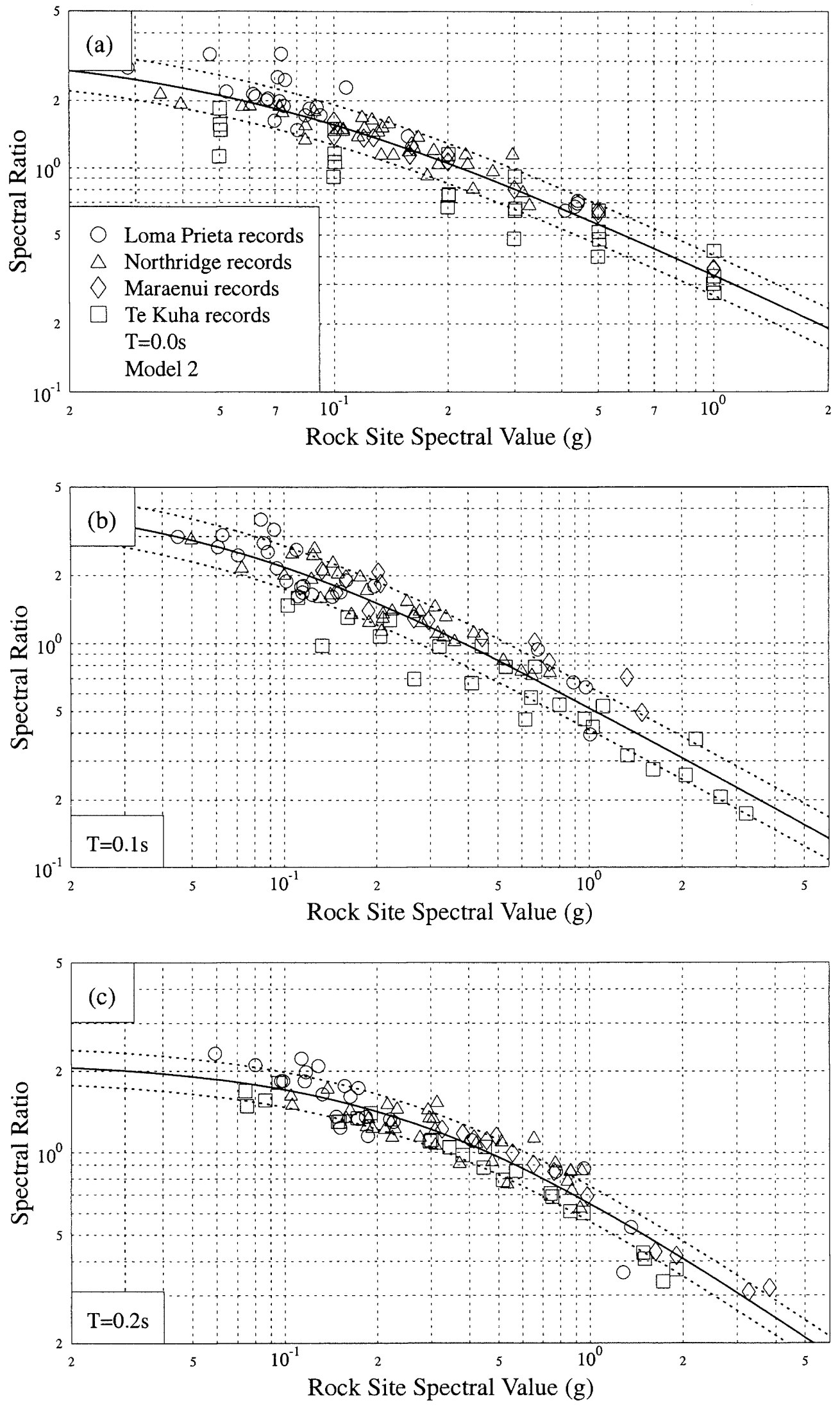

Figure 7: Spectral ratios as a function of rock site spectral values at a given period. The dotted lines are for "mean - $\sigma$ " and "mean $+\sigma$ " curves. The parameters for Equation 1 are also presented, (a) $T=0.0 s,(b) T=0.1 s$, and (c) $T=0.2 s$. The largest scatter occurred for $T=0.1 \mathrm{~s}$. 

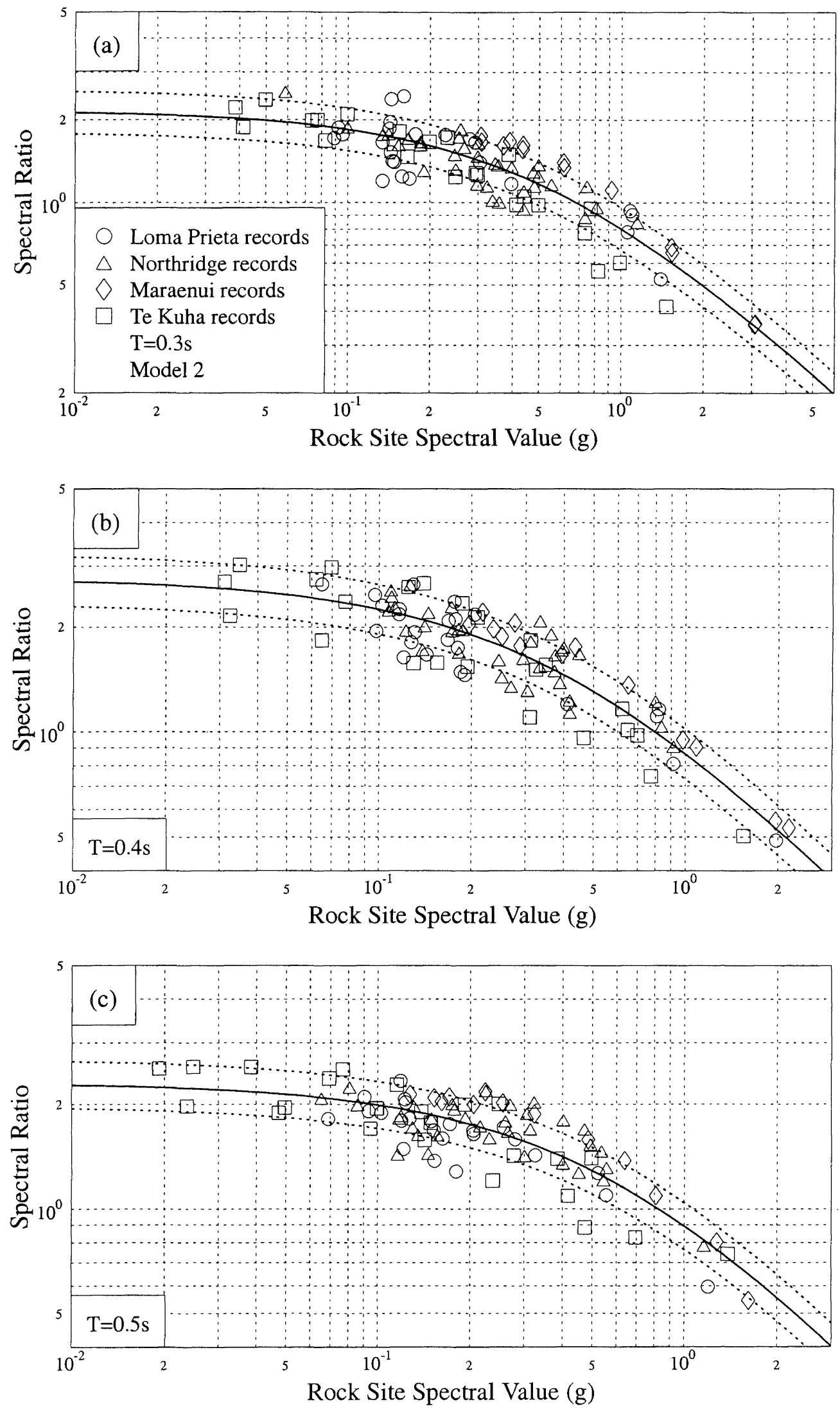

Figure 8: Spectral ratios as a function of rock site spectral values at a given period. The parameters for Equation 1 are also presented, (a) $T=0.3 \mathrm{~s},(\mathrm{~b}) \mathrm{T}=0.4 \mathrm{~s}$, and (c) $T=0.5 \mathrm{~s}$. 

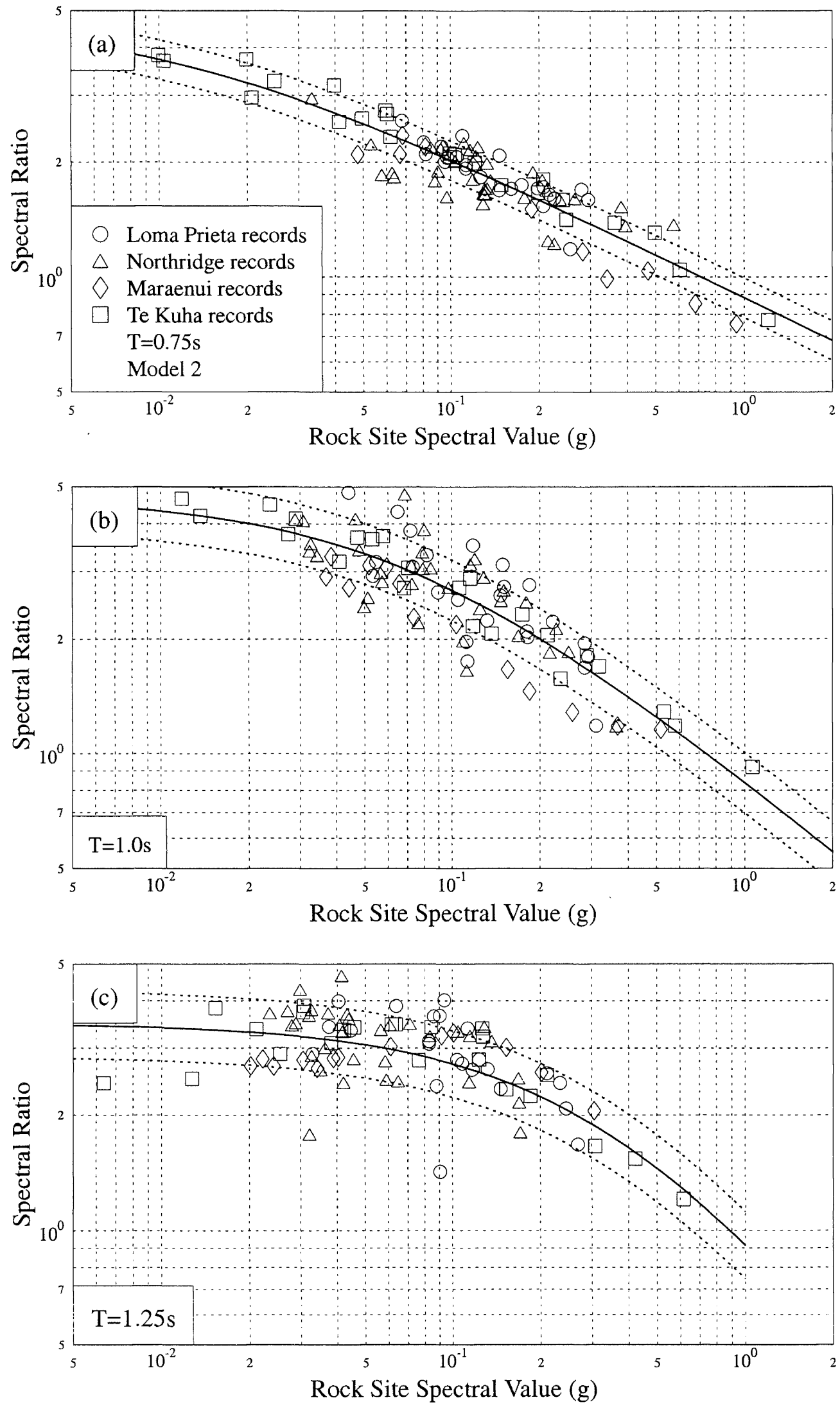

Figure 9: Spectral ratios as a function of rock site spectral values at a given period. The parameters for Equation 1 are also presented, (a) $T=0.75 \mathrm{~s}$, (b) $T=1.0 \mathrm{~s}$, and $(c) T=1.25 \mathrm{~s} . T=0.75 \mathrm{~s}$ has the smallest scatter. 

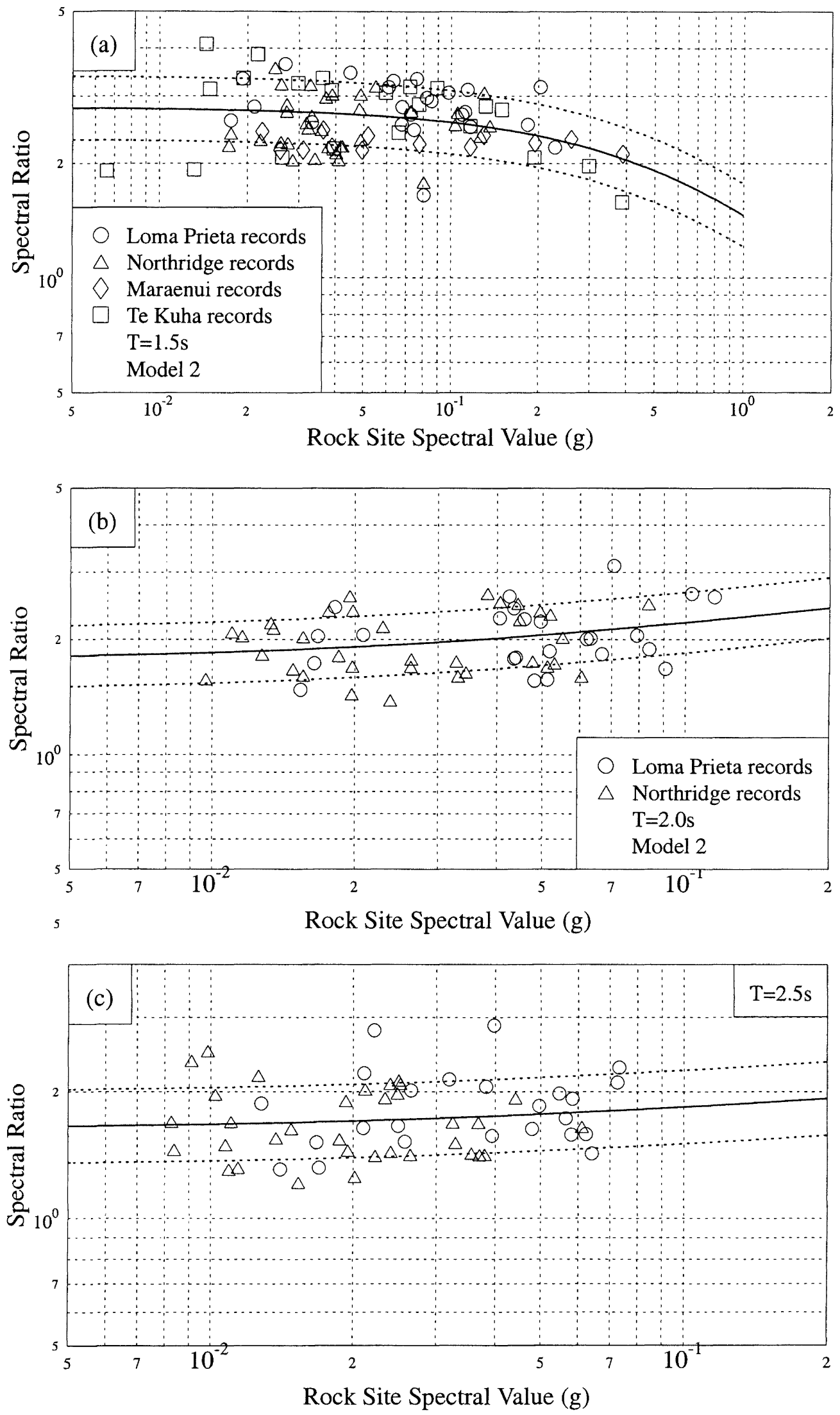

Figure 10: Spectral ratios as a function of rock site spectral values at a given period. The parameters for Equation 1 are also presented, (a) $T=1.5 \mathrm{~s}$, (b) $T=2.0 \mathrm{~s}$, and (c) $T=2.5 \mathrm{~s}$. 

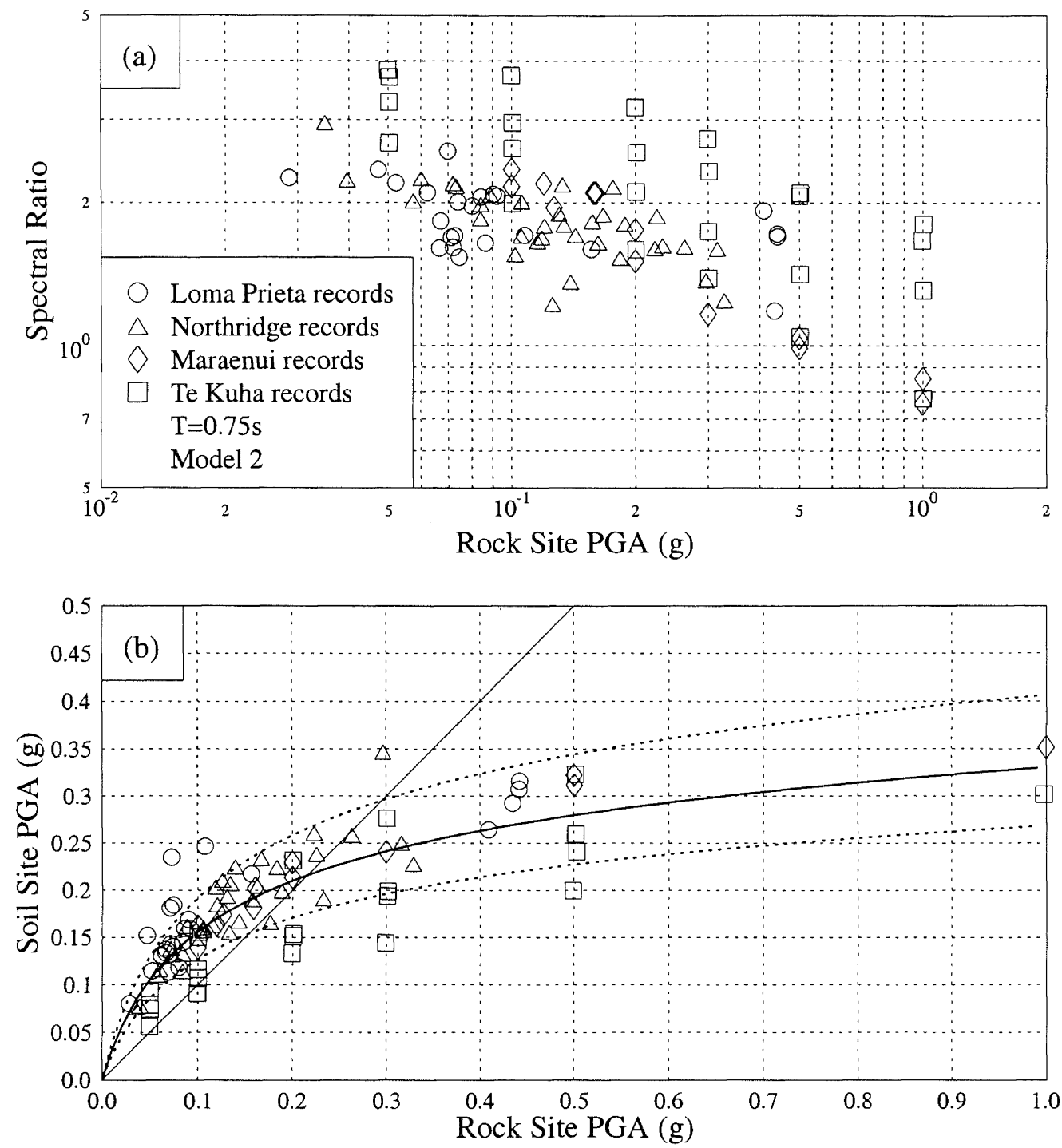

Figure 11: Spectra ratios versus rock site PGAs for $T=0.75 s$ (a), and soil site PGAs computed from the non-linear soil model versus rock site PGAs (b).

\section{A SITE SPECIFIC SMOOTHED RESPONSE SPECTRUM}

To estimate a design response spectrum for a particular soil site; basically two approaches can be taken. A probabilistic spectrum can be estimated for a given level of probability of exceedance using an attenuation model appropriate for the site condition. However, soft soil sites such as the Gisborne Post Office site are not usually well represented in the data set that is used to derive attenuation models and they are often not even included in the model $[24,27]$. Many researchers suggest specific site investigation for such kind of soft soil sites [22, 26]. Also for a highly resonant site like the Gisborne Post Office site, an attenuation model will almost certainly underestimate the spectral values in a period band about the "apparent" fundamental mode, because of the effectively averaging procedure in a regression analysis using records from many sites. Alternatively, non-linear modelling can be performed and the input excitation can be either an artificial record obtained by fitting an estimated probabilistic rock site response spectrum for a given level of probability exceedance [28], and/or a suite of rock site recorded motions possibly with amplitudes and/or period being scaled. A smoothed design spectrum can then be derived based on the simulated data.

A different approach is used in this paper to produce a smoothed spectrum for this specific site. A probabilistic spectrum is derived first for a rock site and then spectral ratios shown in Figures 7-10 can be used to evaluate the soil site spectrum. The probabilistic spectra shown in Figure 12 for ground class I (rock site with or without a layer of stiff soil less than $10 \mathrm{~m}$ thick) and IV (soft alluvial layer or reclaimed land with depth larger than $25 \mathrm{~m}$ ) are based on the modified 1982 Katayama attenuation model $[29,31]$ and the 1992 SmithBerryman seismicity model [30], assuming uniformly distributed earthquake sources within regional seismic zones. The probabilistic response spectra are very similar to those presented by Matushchka et al. [31] on which the current New Zealand Loadings Code [32] is based. The probabilistic rock site spectrum was multiplied by the mean and "mean $+\sigma$ " 
spectral ratios shown in Figures 7-10 to derive the soil site spectrum shown in Figure 12 for 150 and 450 year return periods. Figure 12 shows that for both return periods, the soil spectra derived by using the mean spectral ratios are considerably smaller than the probabilistic soil spectra for ground class IV at periods up to $1.0 \mathrm{~s}$ and the differences are larger for 450 year than for 150 year return period. At long periods ( $>1.25 \mathrm{~s})$ the mean soil spectra are almost identical to those of the probabilistic soil spectra. The spectra derived in this paper have a gentle peak at the site "apparent" fundamental period of $1.0-1.25 \mathrm{~s}$, as expected, and the shape of the peak is very similar to that of the mean recorded spectra shown in Figure 4(c). A higher resolution in the spectral period than in Figure 12 would possibly give a somewhat higher peak in the period band of 1.0- 1.25s than that shown in Figure 12, and it is obvious that the "apparent" fundamental modal period is slightly longer for 450 year than for 150 year return period.

The following explanation can be given for the differences between the probabilistic soil spectra and the mean spectra produced in the present paper. In the data set compiled by Katayama, there is a small number of records for Ground classes I (39) and IV (36), and these records are mainly from earthquakes of $20 \mathrm{~km}$ or more away from recording stations and have small spectral amplitude. The number of records from a site similar to the Gisborne Post Office site would be most likely very small if any, because this site is unusually soft (see discussions later in the present paper). The Katayama attenuation model does not account for non-linear site effects and non-linearity would be minor for most of the records because of their low amplitudes. Even in recent PGA and spectral velocity attenuation models $[18,19]$, non-linear site effects are still not explicitly accounted for (i.e., using constant soil site factors). The lack of non-linear site effects in the attenuation model is a likely cause for the difference between the probabilistic soil site spectra and the mean spectra derived in this paper, with the probabilistic soil site response spectra likely to overestimate the soil site spectra at the shaking level even for 150 year return period. The similarity between the probabilistic soil spectrum and the mean spectrum at long period ( $>1.5 \mathrm{~s}$ ), where soil non-linearly seems not to have a significant effect, is consistent with this explanation.

Even if the attenuation models used to derive a probabilistic soil site spectrum account for soil non-linearity, it is very likely that such an approach used in a standard seismic hazard analysis can possibly under-estimate the spectrum at the "apparent" fundamental modal period for a strongly resonant site and overestimate the spectrum at the other period, because of the averaging effect in the regression procedure in deriving attenuation models.

Berrill et al. [28] used an artificial earthquake motion, derived by matching a probabilistic rock site response spectrum, as the excitation for their non-linear soil models. This approach is also used in this paper. The artificial record was generated by modifying a real earthquake record obtained in Santa Cruz UCSC/Lick Lib. in the 1989 Loma Prieta earthquake to match the probabilistic rock site response spectrum. The computed response spectrum for the modelled site motion is shown in Figure 13, compared with the probabilistic soil site spectrum and the mean and "mean $+\sigma$ " spectra. Figure 13 shows that the response spectrum given by the analysis of the non-linear model generally varies between the mean and the "mean $+\sigma$ " spectra, as expected. At the "apparent" fundamental modal period of the site (between $1.0-1.25 \mathrm{~s}$ ), the spectral values obtained from the non-linear analysis are about the same as the "mean $+\sigma$ " spectrum and the "mean $+\sigma$ " spectrum is almost an envelop of the spectrum from the non-linear analysis.

Figures 12 and 13 show that the soil site spectrum obtained by using the spectral ratios can give a smoothed site specific spectrum and the "mean $+\sigma$ " spectrum can possibly be used as an envelope for the site-specific spectrum.

\section{DISCUSSION ON THE MODELLING RESULTS}

Recently, seismic soil site response studies have attracted a large amount of attention from engineering communities. Considerable effort was put into classifying strong motion site conditions [6] and strong motion record analyses [22, 26] Quantitative site class definitions have been presented $[22,26]$ and the number of site classes increased compared with that used in many design codes. The Gisborne Post Office site can be classified as $D_{2}$ according to the description given in Crouse and McGuire [22] and as $D_{1}$ or $E_{1}$ according to the description presented by Dickenson and Seed [26]. Dickenson and Seed also presented plots for the relationship between soil site PGAs and rock site PGAs for various site classes so that "a slightly conservative estimate" of soil site PGA could be provided. The curve for ground classes $C_{4}+D+E$, all soft soil sites, has a cross over point at $0.4 \mathrm{~g}$, i.e., a soil site PGA will be less than that of a nearby rock site if the rock site PGA exceeds $0.4 \mathrm{~g}$. This cross over point is significantly larger than that presented in Figure 11(b) estimated as $0.22 \mathrm{~g}$ on average for the Gisborne Post Office site. The following explanation can be given for this large difference.

(1) A major reason for the low cross-over point in Figure 11 (b) is the shear modulus reduction curves for the soil samples of the Gisborne Post Office site as shown in Figures 1 and 2. If testing were not carried out and published relationships were selected for the soil samples according to the soil description and plasticity index (described as the most influential and consistent soil parameter for clay [14]), the C3 model would have been selected for the soils at depth $0-7 \mathrm{~m}$ and the $\mathrm{C} 4$ model for the other soil layers. Such a soil site non-linear model would give a cross over point at about $0.35 \mathrm{~g}$ under the 1994 Northridge earthquake records, slightly less than $0.4 \mathrm{~g}$ as suggested by Dickenson and Seed [26]

(2) The average shear wave velocity for the top $30 \mathrm{~m}$ of a soil site has been used as the basis for site classification $[20,22,34]$. The average shear wave velocity for the top $30 \mathrm{~m}$ of the Gisborne Post Office site is only $139 \mathrm{~m} / \mathrm{s}$, much lower than the upper bound $(180 \mathrm{~m} / \mathrm{s})$ for Ground Class E, adopted by the National Earthquake Hazard Reduction Program (NEHRP) [34], suggesting that the Gisborne Post Office site is a very soft soil site. Because the low shear wave velocity results in a low soil shear strength for a same shear modulus reduction curve, the low value for the cross over point in Figure 11(b) is most likely to be partially caused by the low values of the average shear wave velocity of the site. 

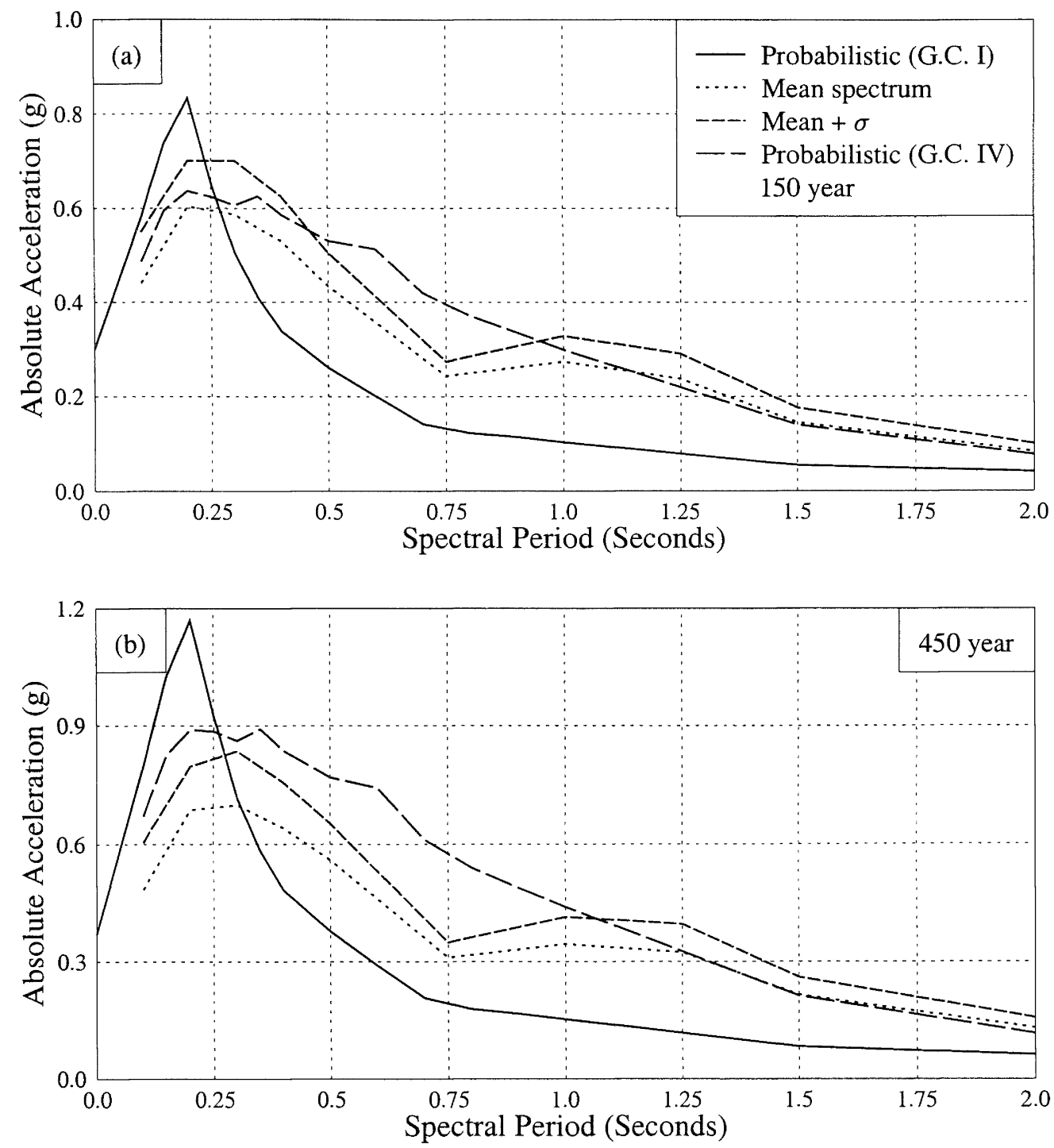

Figure 12: Comparison of probabilistic spectra from rock site (Ground class I) and soil site (Ground class IV) and the site specific smoothed spectra derived from the soil non-linear models for the Gisborne Post Office site, (a) 150 year return period, and (b) 450 year return period.

Two ground site records with small PGAs $(0.06 \mathrm{~g}$ in the 1982 record and $0.095 \mathrm{~g}$ in the 1985 record) suggested that the site was a strongly resonant site [4]. Because of high amplification, soil non-linearity has marked effects for a relatively low rock site PGA.

A note of caution must be exercised when using the spectral ratios presented in Figures 7-10 for an engineering application when a large rock motion is expected, because (1) the nonlinear models established in the present paper were based on a very limited amount of experimental data and a large extrapolation had to be employed for estimating shear stresses developed from a large shear strain expected from large ground shaking, and (2) the unscaled records from the 1989 Loma Prieta and the 1994 Northridge earthquakes used in this paper had a maximum PGA of just over $0.4 \mathrm{~g}$. The spectral ratios obtained in this paper would be plausible for the rock motions at a level similar to those presented in Figure 12.

The modelling results indicates that the ground records with a mean PGA of $0.22 \mathrm{~g}$ obtained in the 1993 Ormond earthquake were significantly affected by soil non-linearity. Without nonlinear effects, it is expected that the records would have had a significantly larger mean PGA than the recorded one.

Near source rock site motions were not used in this paper because there are no known active faults close to Gisborne City. There is also a concern that a soft soil site, like the Gisborne Post Office site, would possibly experience severe ground failure, when subjected to a shaking level similar to those of the near-source motions recorded in the 1994 Northridge earthquake, and the present non-linear models are not sufficient to model such soil deformation. 

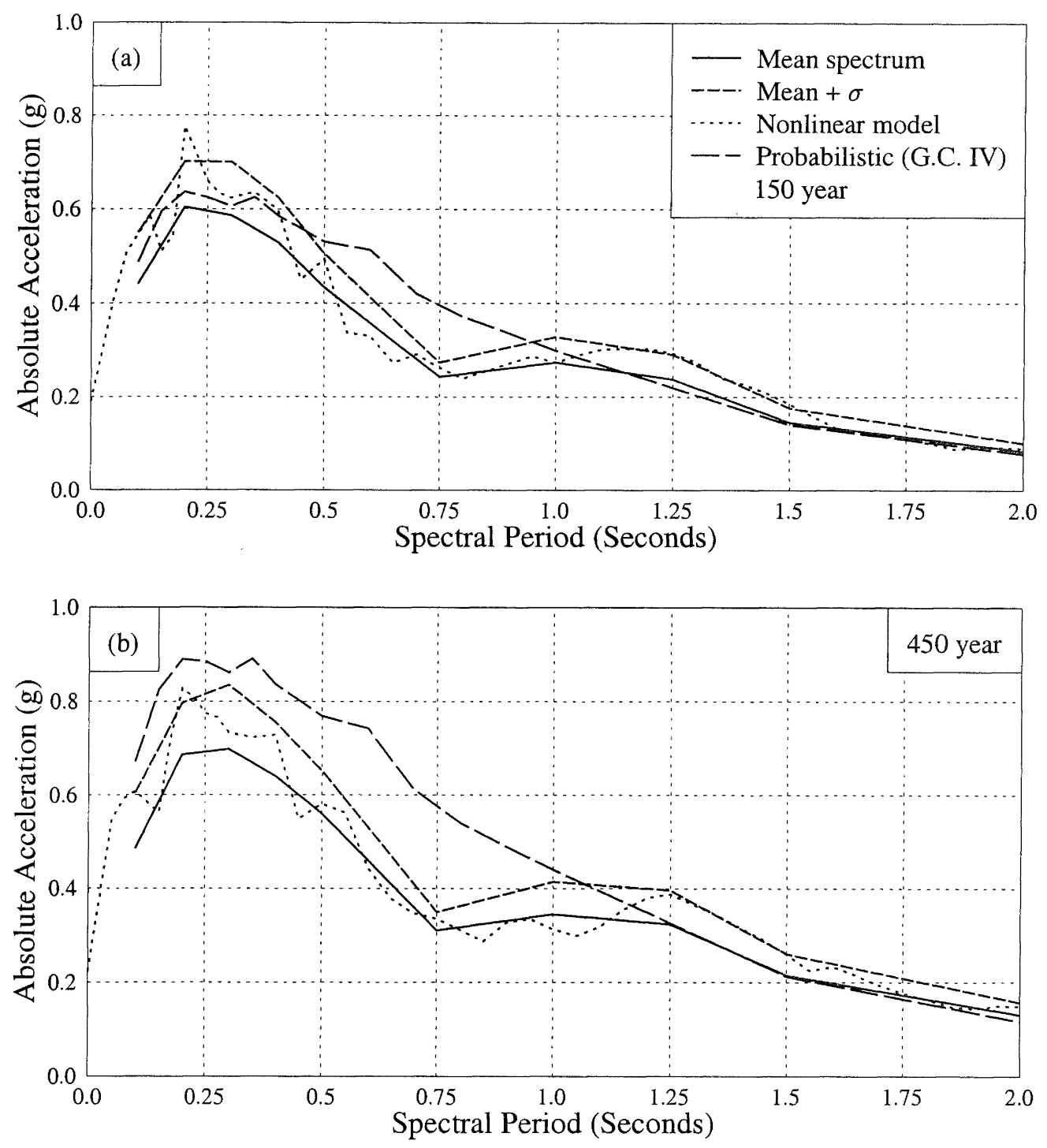

Figure 13: Comparison of the site specific smoothed spectra derived from the soil non-linear models, the computed spectra from non-linear analysis using an artificial record and the probabilistic spectrum for ground class $I V$, (a) 150 year return period, and (b) 450 year return period.

\section{COMPARISON BETWEEN NONLINEAR AND EQUIVALENT LINEAR ANALYSES}

The equivalent linear approach is a very popular method for calculating seismic soil site response in engineering practice. This method is an approximate one in terms of the mathematical treatment of soil non-linear material behaviour while the true non-linear analysis employed in the Densor computer program [12] is "exact". A comparison of the ground surface responses from the two methods is presented in this paper. Model 2 presented in an earlier section is used and damping curves from the experimental data were used for the SHAKE program [11]. The version of SHAKE used in this paper allows the user to specify a parameter $\mathrm{n}$ that defines the fraction of the peak shear strain developed in the mid-point of each layer to be used as the effective shear strain. The effective shear strain is the value used for evaluating equivalent shear modulus and damping ratios. A widely used value has been $\mathrm{n}=$ 0.65 and an earthquake magnitude-dependent value from 0.3 to
0.5 was suggested [33] for significant improvement over $n=$ 0.65. In the program manual for SHAKE91, an earthquake magnitude dependent $n$ value between 0.4 and 0.75 was suggested, indicating the approximate approach in dealing with soil non-linearity. In this paper, a fixed value of 0.5 was used.

The Maraenui record (S50E component) was scaled to give various PGA from $0.05 \mathrm{~g}$ to $1.0 \mathrm{~g}$ and used as the excitation for the soil model. The calculated PGAs are plotted in Figure 14(a) as a function of the PGA of the bedrock input motion. Figure 14(a) shows that the PGAs evaluated by the two methods are generally very similar at low to moderate level of bedrock excitation and significantly different at a high level of bedrock excitation. The PGAs computed by SHAKE are slightly smaller than those by the non-linear approach for rock site PGAs of $0.2 \mathrm{~g}$ or less and are significantly higher than those of the non-linear approach at $0.5 \mathrm{~g}$ and $1.0 \mathrm{~g}$ bedrock PGAs. The response spectra for a bedrock PGA of $0.1 \mathrm{~g}$ and $0.5 \mathrm{~g}$ are shown in Figures 14(b) and 14(c). At very short periods $(0.1-0.2 \mathrm{~s})$, 
the two methods give significantly different spectral values and for long periods $(>0.5 \mathrm{~s}$ ) the two methods give very similar spectral values for different levels of bedrock excitation. In the intermediate period range $(0.2-0.5 \mathrm{~s})$, SHAKE gives a much higher (about $50 \%$ ) spectral values than the non-linear program Densor for the bedrock motions with a PGA of $0.5 \mathrm{~g}$ but gives a very similar spectrum to that of Densor for the bedrock motions with a PGA of $0.1 \mathrm{~g}$. Unscaled earthquake rock site motions from the 1989 Loma Prieta earthquake were also used for comparison and the trend was very similar to those shown in Figure 14. Comparison was also made for a model with the top $20 \mathrm{~m}$ of soil having a much larger shear strength than model 2 and the differences between the two methods were considerably smaller than those shown in Figure 14.

\section{GENERAL CONCLUSIONS}

Results from site investigation and geotechnical testing of soils at the Gisborne Post Office site in Gisborne, New Zealand, were presented in this paper. Nonlinear soil models based on these results were established and seismic responses of the site were estimated. The following general conclusions can be made in the present study.

Results from the site investigation and geotechnical testing on soil samples taken from this site show that the site is a soft soil site, suggesting that it is susceptible to ground motion amplification. The mean-shear wave velocity of the top $30 \mathrm{~m}$ of soil (total thickness of $40 \mathrm{~m}$ ) is about $140 \mathrm{~m} / \mathrm{s}$, significantly lower than the soil sites usually included in the data set for developing the recent New Zealand strong motion attenuation model [18]. This site is unusually soft, and it is suggested that it should be subjected to a specific site investigation if it is necessary to estimate a future earthquake ground motion for engineering design.

Results from the geotechnical testing of soil samples from the site indicate that the shear modulus reduction curves in the strain amplitude range of $0.001-0.2 \%$ are significantly lower than the published results in the literature for soils with a similar value of plasticity index. Sample disturbance is unlikely to be the reason because the measured shear wave velocities at a very small strain amplitude are very consistent with those obtained from in-situ measurements.

The results of a sensitivity study suggest that the response spectra for the calculated surface motions of the modelled site are not very sensitive to changes in the maximum shear strain at which the soil shear strength is reached from $1 \%$ to $2 \%$ for soil layers at depths of $0-7 \mathrm{~m}$. The response spectra of the surface motions are not very sensitive either to a change of $30 \%$ in shear strength for soils at depths of $10-20$ m. A $40 \%$ increase in shear wave velocity for the bottom $8 \mathrm{~m}$ of soil (between $32 \mathrm{~m}$ and $40 \mathrm{~m}$ depth) or changing the non-linear model from $\mathrm{C} 3$ to $\mathrm{C} 4$ model (Sun et al. [14]) for the bottom $16 \mathrm{~m}$ of soil ( $24 \mathrm{~m}-40 \mathrm{~m}$ depth) have little effect on the model surface response spectra.
A non-linear stress-strain model for the soil site based on the best estimate of the soil material parameters was used to predict the ground motions obtained in the 1993 Ormond earthquake. Using a soil site factor of a recent PGA attenuation model [18], the mean PGA of a rock outcrop site close to the Gisborne Post Office site would be approximately estimated to be $0.14 \mathrm{~g}$. The record from the Maraenui site obtained from the same earthquake and a modified version (eliminating the effect of a possible thin layer of soil over the rock at the Maraenui site) scaled to have a PGA of $0.14 \mathrm{~g}$ were then used as the bedrock excitation. The mean acceleration and displacement spectra produced by the modified Maraenui records compared reasonably well with the recorded ones, suggesting that the nonlinear soil model for the Gisborne Post Office site is plausible.

(5) A suite of rock site motions from moderate and large magnitude earthquakes were used as excitations for the non-linear model. Spectral ratios were presented as functions of the spectral values of rock input motions for each spectral period. Non-linear soil behaviour was found to have a first order effect on the variation of spectral ratios, with the scatter in the ratios likely to come from the variation in frequency content of the different bedrock input motions. Soil deamplification for a large bedrock excitation exists for periods up to $1.0 \mathrm{~s}$ within the range of the simulated data, and at long periods ( 2.0 and $2.5 \mathrm{~s}$ ) the spectral ratios tend to increase slightly with the increase in the level of rock site excitation. Soil nonlinearity seems to have little effect on the spectral ratios for periods much longer than the site elastic period of the fundamental mode. This suggests that an elastic analysis which is much simpler and less computationally expensive than a non-linear analysis can possibly be used to reliably predict long-period ground motions of a highly non-linear soil site, provided that damping from other sources can be estimated reliably.

(6) The mean and "mean $+\sigma$ " spectral ratios derived from the non-linear analyses were used to derive sitespecific smoothed spectra and the corresponding envelope spectra for the Gisborne Post Office site, based on probabilistic rock site spectra for 150 and 450 year return periods. The mean spectra derived in this paper have smaller values for periods less than $1.25 \mathrm{~s}$ than the probabilistic spectra for soft soil sites. The discrepancies are largely attributed to the possible lack of records from rock and soft soil site in the Katayama attenuation model [29]. An artificial record, derived by modifying a rock site record from the 1994 Northridge earthquake and matching the probabilistic rock site spectrum, was also used to evaluate the soil site spectrum. The soil site spectrum computed from the artificial record varies between the mean and "mean $\pm \sigma$ " smoothed spectrum. The smoothed spectrum predicts a peak between $1.0-1.5 \mathrm{~s}$ period where the site "apparent" fundamental modal period lies. 

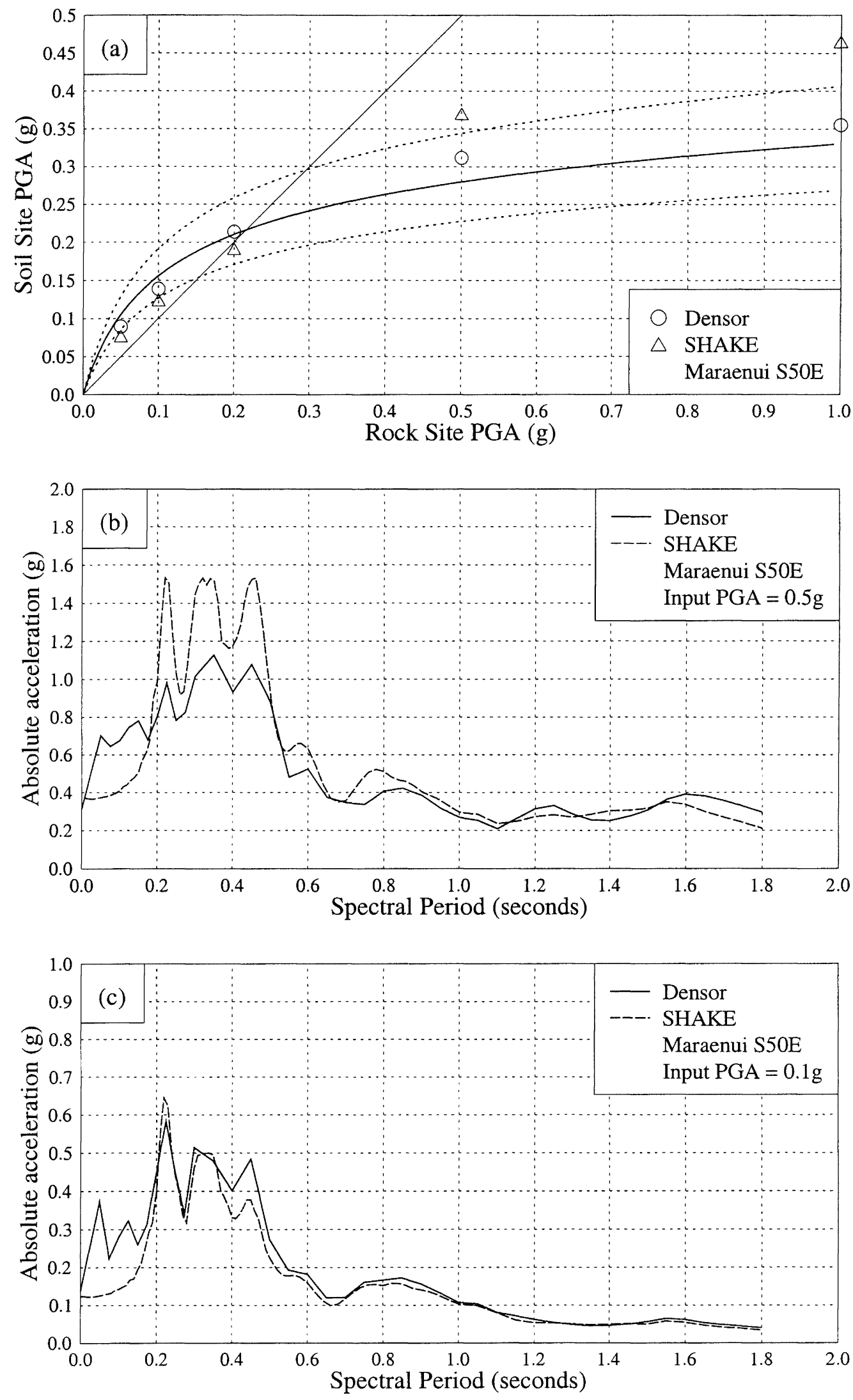

Figure 14: Comparison of the model surface response spectra computed by equivalent linear analysis (SHAKE) and non-linear analysis (Densor) using the Maraenui record (S50E) as the excitation, (a) PGAs and the mean curve as well as the $"$ mean $-\sigma$ " and "mean $+\sigma$ " curves shown in Figure 11(b), (b) response spectra for a rock excitation $P G A=0.5 g$, and (c) response spectra for a rock excitation $P G A=0.1 \mathrm{~g}$. 
The cross-over point, above which a rock site PGA will be deamplified by soil layers, in the relationship between soil site PGAs and rock site input PGAs, appears to be $0.22 \mathrm{~g}$ on average for the modelling in this study, and the cross-over points for "mean $\pm \sigma$ " curves are $0.15 \mathrm{~g}$ and $0.29 \mathrm{~g}$ respectively. It also appears that the PGA relationship would follow the "mean - $\sigma$ " curve for records from small magnitude events and the "mean $+\sigma$ " curve for records from large magnitude events. The average value for the cross-over point estimated for this site is much smaller than $0.4 \mathrm{~g}$ recommended by Dickenson and Seed [26] for this class of site. This low value is attributed to the unusually low soil shear wave velocities for the top $30 \mathrm{~m}$ of soils (e.g. low soil shear strength), and the low values of shear modulus reduction curves compared with the published results for soils with similar plasticity indexes.

A comparison of the results from an equivalent linear method (SHAKE) and a true non-linear method indicates that the equivalent linear method over predicts response spectra in intermediate periods and PGA by a significant amount for a rock site excitation with a PGA of $0.5 \mathrm{~g}$ or more and the difference diminishes for a decrease in the rock site shaking level.

\begin{abstract}
A note of caution must be exercised when using the results presented in this paper for an engineering application because of limitations on the geotechnical testing and numerical simulations. The maximum shear strain in the geotechnical testing is between $0.1-0.2 \%$, corresponding to the level of peak shear strain developed in the model for a bedrock excitation with a PGA about $0.2 \mathrm{~g}$. Test data for large shear strain amplitude, for example $0.5 \%$, should be pursued in future experiments. The spectral ratios presented in this paper within the data range of the 1989 Loma Prieta and 1994 Northridge earthquakes should only be attempted to be used for other sites similar to the Gisborne Post Office site.
\end{abstract}

\section{ACKNOWLEDGEMENT}

The authors wish to thank Drs. Tam Larkin (University of Auckland) and Rob Davis (University of Canterbury) for their review of this manuscript and invaluable suggestions. The nonlinear program and assistance in the non-linear modelling were kindly provided by Dr. Tam Larkin. The research reported here is supported by Foundation for Research Science and Technology of New Zealand, Contract No. C05620.

\section{REFERENCES}

1. Idriss, I.M. (1990), Response of soft soil sites during earthquakes, Proc. Memorial Symp. to honour Professor Harry Bolton Seed, Berkeley California, Vol II, 273-289.

2. Seed, H.B., Romo, M.P., Sun, J., Jaime, A. and Lysmer, J. (1987), Relationships between soil conditions and earthquake ground motions in Mexico city in the earthquake of Sept. 19, 1985, Report No. UCB/EERC87/15, Earthquake Engineering Research Centre, University of California, Berkeley.

3. Bonilla, M.G. (1991), The Marina district, San Francisco California: geology, history and earthquake effects, Bulletin Seism. Soc. of America, 81(5):1958-1979

4. Cousins, W.J., Hefford, R.T., McVerry, G.H. and Downer, R.M. (1987), Computer analyses of New Zealand earthquake accelerograms 1981-1985, Volume 2, PEL, DSIR, Lower Hutt, New Zealand.

5. Cousins, W.J., Porritt, T.E., Hefford, R.T., Baguley, D.E., O'Kane, S.M. and McVerry, G.H. (1994), Computer analyses of New Zealand earthquake accelerograms, Volume 8, Institute of Geological \& Nuclear Sciences, Lower Hutt, New Zealand.

6. Cousins, W.J., N.D. Perrin, McVerry, G.H., Hefford, R.J. and Porritt, T.E. (1996), Ground conditions at strong motion recording sites in New Zealand, Institute of Geological and Nuclear Sciences, Science Report 96/33, Lower Hutt, New Zealand.

7. Barker, P.R. (1994), A report on cone penetrometer and seismic cone penetrometer testing at selected sites in lower of North Island, Report prepared by Barker Consulting for Engineering Seismology Section, Institute of Geological \& Nuclear Sciences.

8. Marsh, J., Larkin, T.J., Haines, A.J. and Benites, R.A (1995), Comparison of linear and non-linear seismic responses of two-dimensional alluvial basins, Bull. Seism. Soc. Am., 85(3):874-889.

9. Stepp, J.C. and Cramer, C.H. (1992), A brief summary of the results of the Turkey Flat weak motion site response blind prediction, Proceedings of the Tenth World Conference on Earthquake Engineering, Madrid, Spain, 11:6963-6965

10. Shinozaki, Y. and Irikura, K. (1992), Summary and some comments on results of Ashigara Valley blind prediction test, Proceedings of the Tenth World Conference on Earthquake Engineering, Madrid, Spain, 11:6973-6976.

11. Schnabel, P.B. and Lysmer, J. (1972), SHAKE - A computer program for earthquake response analysis of horizontally layered sites, Report No. UCB/EERC-72/12, Earthquake Engineering Research Centre, University of California, Berkeley.

12. Larkin, T.J. (1998), DENSOR - A computer program for seismic analysis of non-linear horizontally layered soil sites. Department of Civil and Resource Engineering, The University of Auckland.

13. Pender, M. and Larkin, T. (1994), Dynamic soil properties of soil samples from Gisborne and Wairoa, Report prepared for Institute of Geological and Nuclear Sciences, Auckland Uniservices Ltd., The University of Auckland. 
14. Sun, J., Golesorkhi, R. and Seed, H.B. (1988), Dynamic moduli and damping ratios for cohesive soils, Report No. $U C B / E E R C-88 / 15$, Earthquake Engineering Research Centre, University of California, Berkeley.

15. Zhao, J.X. (1998), The estimation of structural modal parameters from the responses of the Gisborne Post Office building in recent earthquakes, Bulletin of the New Zealand National Society for Earthquake Engineering, 31:51-63.

16. Duske, G.C., Meyer, V. and Larkin, T.J. (1997), Dynamic torsion tests of soil samples from Atene, Report prepared for Dr. G. McVerry, Engineering Seismology Section, Institute of Geological and Nuclear Sciences, Auckland Uniservices Ltd., The University of Auckland.

17. Zhao, J.X. (1996), Estimating modal parameters for a simple soft-soil site with a straight line distribution of shear wave velocities, Earthquake Engineering and Structural Dynamics, 25:163-178.

18. Zhao, J.X., Dowrick, D.J. and McVerry, G.H. (1997), Attenuation of peak ground accelerations in New Zealand earthquakes, Bulletin of the New Zealand National Society for Earthquake Engineering, 30(2):133-158.

19. Boore, D.M., Joyner, W.B. and Fumal, T.E. (1993), Estimation of response spectra and peak accelerations from Western North American earthquakes: an interim report, Part 1, Open-File Report 93-509, U.S. Geological Survey, Menlo Park.

20. Boore, D.M., Joyner, W.B. and Fumal, T.E. (1994), Estimation of response spectra and peak accelerations from Western North American earthquakes: an interim report, Part 2, Open-File Report 94-127, U.S. Geological Survey, Menlo Park.

21. Chin, B.H. and Aki, K. (1991), Simultaneous study of the source, path, and site effects on strong ground motion during the 1989 Loma Prieta earthquake: a preliminary result on pervasive non-linear site effects, Bulletin Seism. Soc. of America, 81(5):1338-1858.

22. Crouse, C.B. and McGuire, J.W. (1991), Site response studies for purpose of revising NEHRP seismic provisions, Earthquake Spectra, 12(3), 407-439.

23. Chang, S.W., Bray, J.D. and Seed, R.B. (1996), Engineering implications of ground motions from the Northridge earthquake, Bulletin Seism. Soc. of America, 86(1), Part B, Supplement, S270-288.

24. Abrahamson, N. and Silva W. (1996), Empirical response spectral attenuation relations for shallow crustal earthquakes, Seismological Research Letters, 68(1):94127.

25. Idriss, I.M. (1991), Earthquake ground motions at soft soil sites, Proc. Second International Conference on Recent Advances in Geotechnical Earthquake Engineering and Soil Dynamics, St Louis, Missouri, Vol. III, 2265-2272.
26. Dickenson, S.E. and Seed, R.B. (1996), Nonlinear dynamic response of soft and deep cohesive soil deposits, Proceedings of the international workshop on site response subjected to strong earthquake motions, Yokosuka, Japan, 2:67-81

27. McVerry, G.H., Zhao, J.X., Dowrick, D.J., Abrahamson, N. and Somerville, P. (1997), Progress in developing attenuation models for strong earthquake ground motions in New Zealand, Report prepared for ECNZ by Institute of Geological and Nuclear Sciences.

28. Berrill, J.B., Davis, R.D. and McCahon, I.F. (1993), Christchurch seismic hazard pilot study, Bulletin New Zealand National Society for Earthquake Engineering, 26(1), 14-27.

29. Katayama, T. (1982), An Engineering prediction model of acceleration response spectra and its application to seismic hazard mapping, Earthquake Engineering and Structural Dynamics, 10:149-163.

30. Smith, W.D. and Berryman, K.R. (1992), Earthquake hazard estimates for New Zealand: Effects of changes in the seismicity model, Report to the EQC, DSIR Geology and Geophysics.

31. Matushchka, T., Berryman, K.R., O'Leary, A.J., McVerry, G.H., Mulholland, W.M. and Skinner, R.I. (1985), New Zealand seismic hazard analysis, Bulletin New Zealand National Society for Earthquake Engineering, 18(4):313-322.

32. NZS4203:1992, Code of practice for general structural design and design loadings for buildings, Standards New Zealand, Wellington.

33. Dickenson, S.E., Seed, R.B., Lysmer, J. and Mok, C.M. (1991), Response of soft soils during the 1989 Loma Prieta earthquake and implications for seismic design criteria, Proceedings of the Pacific Conference on Earthquake Engineering, Auckland, New Zealand, 3:191-203.

34. BSSC (1994), NEHRP recommended provisions for seismic regulations for new buildings, Part I - Provisions, FEMA 222A, Federal Emergency Management Agency, 290pp. 